\title{
Supporting Information for Carotenoid Nuclear Reorganization and Interplay of Bright and Dark Excited States
}

Elliot J. Taffet, ${ }^{1}$ Benjamin G. Lee, ${ }^{2}$ Zi S.D. Toa, ${ }^{1}$ Natalie Pace,${ }^{2}$ Garry Rumbles,${ }^{2}$ June Southall, ${ }^{3}$ Richard J. Cogdell ${ }^{3}$ and Gregory D. Scholes*1

1. Department of Chemistry, Princeton University, Princeton, New Jersey 08544, United States

2. Chemical and Materials Science Center, National Renewable Energy Laboratory, Golden, Colorado 80401, United States

3. Institute of Molecular, Cell and Systems Biology, College of Medical Veterinary and Life Sciences, University of Glasgow, University Avenue, Glasgow G12 8QQ, UK. 
Table S1. MRPT Singlet and Triplet Excitation Energies (in eV) for the Carotenoids (Top to

Bottom) Neurosporene, Spheroidene, $\beta$-Carotene, Lycopene and Spirilloxanthin With Respect to Active Space Size (Ordering of States Determined by DMRG-SCF).

\section{Neurosporene ( $\mathbf{N}=9$ )}

\begin{tabular}{|l|l|l|l|l|l|l|l|l|l|}
\hline State & Multiplicity & $(4,4)$ & $(6,6)$ & $(8,8)$ & $(10,10)$ & $(12,12)$ & $(14,14)$ & $(16,16)$ & $(18,18)$ \\
\hline 1 & 1 & 3.26 & 3.53 & 3.39 & 3.29 & 3.17 & 3.16 & 3.11 & $\mathbf{2 . 9 6}$ \\
\hline 2 & 1 & 2.88 & 2.91 & 3.06 & 2.98 & 3.96 & 4.03 & 3.76 & $\mathbf{3 . 6 7}$ \\
\hline 3 & 1 & & 5.24 & 4.35 & 4.25 & $\mathbf{2 . 8 4}$ & 4.73 & 4.55 & $\mathbf{4 . 3 4}$ \\
\hline 4 & 1 & & & & & 4.69 & 2.71 & 4.69 & 4.59 \\
\hline 1 & 3 & & 1.74 & 1.69 & 1.65 & & & & \\
\hline 2 & 3 & & 2.86 & 2.73 & 2.63 & & & & \\
\hline
\end{tabular}

\section{Spheroidene $(\mathbf{N}=10)$}

\begin{tabular}{|l|l|l|l|l|l|l|l|l|l|l|}
\hline St. & Mult. & $(4,4)$ & $(6,6)$ & $(8,8)$ & $(10,10)$ & $(12,12)$ & $(14,14)$ & $(16,16)$ & $(18,18)$ & $(20,20)$ \\
\hline 1 & 1 & 3.26 & 3.44 & 3.28 & 3.12 & 3.08 & 3.05 & 2.93 & 2.83 & $\mathbf{2 . 7 9}$ \\
\hline 2 & 1 & 2.71 & 2.82 & 3.44 & 3.67 & 3.85 & 3.72 & 3.59 & 3.48 & $\mathbf{3 . 4 3}$ \\
\hline 3 & 1 & & 5.20 & 3.79 & 3.10 & 2.72 & $\mathbf{2 . 7 3}$ & 4.18 & 4.13 & $\mathbf{4 . 0 5}$ \\
\hline 4 & 1 & & & 5.57 & 4.59 & 4.73 & 4.71 & 2.63 & 4.22 & 4.27 \\
\hline 5 & 1 & & & & 5.05 & 4.92 & 4.80 & & 2.68 & 2.46 \\
\hline 6 & 1 & & & & & & & & & 4.70 \\
\hline 1 & 3 & 1.62 & 1.70 & 1.65 & 1.61 & 1.58 & 1.58 & 1.55 & 1.59 & 1.50 \\
\hline 2 & 3 & 2.66 & 2.79 & 2.57 & 2.38 & 2.37 & 2.36 & 2.15 & 2.12 & 2.12 \\
\hline
\end{tabular}




\section{B-Carotene $(\mathrm{N}=11)$}

\begin{tabular}{|l|l|l|l|l|l|l|l|l|l|l|l|}
\hline St. & Mu. & $(4,4)$ & $(6,6)$ & $(8,8)$ & $(10,10)$ & $(12,12)$ & $(14,14)$ & $(16,16)$ & $(18,18)$ & $(20,20)$ & $(22,22)$ \\
\hline 1 & 1 & 3.36 & 3.42 & 3.28 & 3.14 & 3.30 & 3.04 & 3.01 & 3.10 & 2.97 & $\mathbf{2 . 8 4}$ \\
\hline 2 & 1 & 2.73 & 2.86 & 2.86 & 2.71 & 3.85 & 3.56 & 3.63 & 3.69 & $\mathbf{3 . 5 9}$ & 3.75 \\
\hline 3 & 1 & & 4.35 & 4.14 & 4.15 & 3.08 & 2.97 & $\mathbf{2 . 7 6}$ & 4.38 & 4.28 & $\mathbf{4 . 1 8}$ \\
\hline 4 & 1 & & & & 4.91 & 5.42 & 4.62 & 4.28 & 2.49 & 4.55 & 4.39 \\
\hline 5 & 1 & & & & 4.22 & 5.44 & 4.86 & & & 2.41 & 4.75 \\
\hline 1 & 3 & 1.61 & 1.65 & 1.76 & 1.61 & 1.64 & 1.57 & & 1.59 & 1.54 & 1.52 \\
\hline 2 & 3 & 2.80 & 2.85 & 2.62 & 2.42 & 2.62 & 2.41 & & 2.39 & 2.28 & 2.20 \\
\hline
\end{tabular}

\section{Lycopene ( $N=11)$}

\begin{tabular}{|l|l|l|l|l|l|l|l|l|l|l|l|}
\hline St. & Mu. & $(4,4)$ & $(6,6)$ & $(8,8)$ & $(10,10)$ & $(12,12)$ & $(14,14)$ & $(16,16)$ & $(18,18)$ & $(20,20)$ & $(22,22)$ \\
\hline 1 & 1 & 3.22 & 3.29 & 3.19 & 3.08 & 3.02 & 2.94 & 2.87 & 2.93 & 2.79 & $\mathbf{2 . 6 9}$ \\
\hline 2 & 1 & 2.63 & 2.77 & 2.85 & 3.27 & 3.53 & 3.57 & 3.47 & 3.70 & 3.45 & $\mathbf{3 . 2 5}$ \\
\hline 3 & 1 & & 4.24 & 3.97 & 2.98 & 2.81 & $\mathbf{2 . 6 6}$ & 2.61 & 4.43 & 4.14 & $\mathbf{3 . 8 7}$ \\
\hline 4 & 1 & & & 4.77 & 4.74 & 4.49 & 4.26 & 4.00 & 4.63 & 4.33 & 4.06 \\
\hline 5 & 1 & & & & & 4.69 & & 4.41 & 2.66 & 4.78 & 4.41 \\
\hline 6 & 1 & & & & & & & 4.70 & & 2.82 & 4.56 \\
\hline 7 & 1 & & & & & & & 4.86 & & & 2.33 \\
\hline 1 & 3 & 1.56 & 1.60 & 1.59 & 1.56 & 1.56 & 1.54 & & & & \\
\hline 2 & 3 & 2.69 & 2.72 & 2.55 & 2.36 & 2.31 & 2.34 & & & & \\
\hline
\end{tabular}




\section{Spirilloxanthin $(\mathbf{N}=13)$}

\begin{tabular}{|l|l|l|l|l|l|l|l|l|l|l|l|l|l|}
\hline St. & Mu. & $(4,4)$ & $(6,6)$ & $(8,8)$ & $(10,10)$ & $(12,12)$ & $(14,14)$ & $(16,16)$ & $(18,18)$ & $(20,20)$ & $(22,22)$ & $(24,24)$ & $(26,26)$ \\
\hline 1 & 1 & 3.08 & 3.16 & 2.85 & 2.76 & 2.81 & 2.73 & 2.99 & 2.98 & 2.83 & 2.83 & 2.58 & $\mathbf{2 . 5 2}$ \\
\hline 2 & 1 & 2.51 & 2.66 & $\mathbf{2 . 5 1}$ & 2.48 & 3.40 & 3.28 & 3.88 & & & & & \\
\hline 3 & 1 & & 4.14 & 3.94 & 3.38 & 2.47 & 2.51 & 4.73 & & & & & \\
\hline 4 & 1 & & & 4.31 & 4.28 & 4.16 & 3.93 & 4.74 & & & & & \\
\hline 5 & 1 & & & & 4.31 & 4.27 & 4.13 & 2.60 & & & & & \\
\hline 6 & 1 & & & & & 4.69 & 4.59 & 5.45 & & & & & \\
\hline 7 & 1 & & & & & & 4.77 & 5.80 & & & & & \\
\hline 1 & 3 & 1.51 & 1.55 & 1.45 & 1.42 & 1.48 & & & & & & & \\
\hline 2 & 3 & 2.58 & 2.58 & 2.26 & 2.10 & 2.10 & & & & & & & \\
\hline
\end{tabular}

Irrespective of carotenoid conjugation length or functionalization, the two lowest-lying triplet excitation energies can be used as guides for the correlated-triplet-pair singlet dark-state excitation energies as computed by spin-state-averaged NEVPT2/DMRG. This agreement between the correlated-triplet-pair excitation energies and those of the triplet linear combinations that comprise these correlated pair states reaffirms the distinction between dark excited states and the dynamically-correlated bright state discerned computationally. While the bright state is identifiable by root flipping between the zeroth-order and second-order calculations that places the dynamically-correlated state energetically below the statically-correlated states, each individual dark state can be assigned its irreducible representation $\left(\mathrm{A}_{\mathrm{g}}\right.$ or $\left.\mathrm{B}_{\mathrm{u}}\right)$ based on mapping to the computed triplet excited states. This mapping is clear at smaller active spaces: the three lowest-lying correlated-triplet-pair dark states of interest are the $2 \mathrm{~A}_{\mathrm{g}}\left(\mathrm{T}_{1}+\mathrm{T}_{1}\right), 2 \mathrm{~B}_{\mathrm{u}}\left(\mathrm{T}_{1}+\mathrm{T}_{2}\right)$ and 
$3 \mathrm{~A}_{\mathrm{g}}\left(\mathrm{T}_{2}+\mathrm{T}_{2}\right)$ states, where $\mathrm{T}_{1}$ is the ${ }^{3} \mathrm{~B}_{\mathrm{u}}$ and $\mathrm{T}_{2}$ is the ${ }^{3} \mathrm{~A}_{\mathrm{g}}$ state. More importantly, however, the lowest-lying dark state - the $2 \mathrm{~A}_{\mathrm{g}}$ irreducible representation - remains above the bright state for all carotenoid calculations at all active spaces considered. While active spaces larger than $(4,4)$ stabilize the statically-correlated dark states by improving the variational calculation prior to the second-order perturbative correction, they also lead to perturbative over-correlation of the bright state as the variational initial guess is made poorer by the configuration expansion to more diffuse orbitals. Thus, while the ordering of states is generalizable across the carotenoid series, the specific effects of active-space expansion are unique to each carotenoid. As detailed below, certain intermediate active spaces lead to artificial configuration-state mixing in the stateaveraged wavefunction that hybridizes the character of the bright $1 \mathrm{~B}_{\mathrm{u}}$ with that of its correlatedtriplet-pair $2 \mathrm{~B}_{\mathrm{u}}$ state counterpart, meaning that the computational results using these active spaces cannot be trusted.

\section{Neurosporene ( $\mathrm{N}=9$ )}

Neurosporene is a linear hydrocarbon carotenoid with no functionalization other than methyl groups. For compact active spaces up to twelve orbitals, the $1 \mathrm{~B}_{\mathrm{u}}$ wavefunction is appropriately balanced between variational static and perturbative dynamic correlation in the calculation, resulting in reasonable calculations of the vertical absorption peak energy. Agreement with the $(4,4)$ calculation of the $1 B_{u}$ excitation energy, which itself agrees with the experimental absorption peak energy in $n$-hexane, is achieved for active spaces as large as $(12,12)$. At this active space, the most accurate (and thus bolded) excitation energy of $2.84 \mathrm{eV}(436 \mathrm{~nm})$ is computed - the zeroth-order variational excitation energy gets progressively smaller from six to twelve active orbitals before becoming worse at 14 active orbitals. Because the variational description of the $1 \mathrm{~B}_{\mathrm{u}}$ state is best at this 12-orbital intermediate active space, the resulting 
excitation energy is more trustworthy than that computed with a 14-orbital active space, which apparently leads to perturbative over-correlation and thus an unreasonably low excitation energy. Importantly, the excitation energy of this dynamically-correlated state at the most compact active space employed - four active orbitals — serves as an important guide in assessing the validity of the computed excitation energies at larger active spaces where bright-state contamination with outlying orbital correlation at the fringes of the active space may compromise the results.

The $(12,12)$ active space also renders the $2 \mathrm{~B}_{\mathrm{u}}$ and $1 \mathrm{~B}_{\mathrm{u}}$ states more configurationally wellresolved, which improves the accuracy of both computed wavefunctions. The $2 \mathrm{~B}_{\mathrm{u}}$ state is fully stabilized at the complete- $\pi(18,18)$ active space with a computed excitation energy of $3.67 \mathrm{eV}$. As the dynamic correlation stabilization of the $2 \mathrm{~B}_{\mathrm{u}}$ dark correlated-triplet-pair state is marginal, this stabilization is the direct result of an improved variational initial guess stemming from the full correlation of all $\pi$ orbitals. Sampling this outlying electron correlation also stabilizes the $2 \mathrm{~A}_{\mathrm{g}}$ and $3 \mathrm{~A}_{\mathrm{g}}$ correlated-triplet-pair dark states, which themselves are lowered in excitation energy to 2.96 and $4.34 \mathrm{eV}$, respectively. While the $2 \mathrm{~B}_{\mathrm{u}}$ and $3 \mathrm{~A}_{\mathrm{g}}$ states have been described as dark intermediates at this conjugation length, they are computed to be well above the verified bright-state excitation energy even when correlating all $\pi$ orbitals at zeroth order. Moreover, the $2 \mathrm{~A}_{\mathrm{g}}$ state is $0.12 \mathrm{eV}$ above the $1 \mathrm{~B}_{\mathrm{u}}$ state when comparing excitation energies from the best variational wavefunctions (from the $(20,20)$ active space for $2 \mathrm{~A}_{\mathrm{g}}$ and from the $(12,12)$ active space for $1 \mathrm{~B}_{\mathrm{u}}$ ). As all $\pi$ electron correlation has been accounted for at the DMRG level, and as the perturbative over-stabilization effect has been properly accounted for, we can deduce with confidence that the $2 \mathrm{~A}_{\mathrm{g}}$ state evolves into the lowest excited state following nuclear reorganization in the $1 \mathrm{~B}_{\mathrm{u}}$ state. The $2 \mathrm{~A}_{\mathrm{g}}$ and $1 \mathrm{~B}_{\mathrm{u}}$ states should be the most strongly interacting excited states due to the energetic near-degeneracy at the Franck-Condon geometry. It should be 
noted that including other core and virtual orbitals beyond the complete $\pi$ orbital basis results in a poorer variational initial guess for the excited-state wavefunctions and, in turn, overestimated dark-state excitation energies.

\section{$\underline{\text { Spheroidene }(\mathrm{N}=10)}$}

Unlike neurosporene, spheroidene features more intricate functionalization that includes a carbonyl moiety out of conjugation with the planar polyene backbone. The $1 \mathrm{~B}_{\mathrm{u}}$ state is welldescribed by several active spaces employed, with the $(14,14)$ active space yielding the best variational initial guess, and thus the most trustworthy absorption peak energy. The $2.73 \mathrm{eV}$ excitation energy $(455 \mathrm{~nm})$ yielded from this active space compares favorably with that determined experimentally in n-hexane in addition to the $(4,4)$ result. Nonetheless, results from the $(6,6)$ and $(8,8)$ active spaces reveal the parasitic effect of configuration-state mixing within the $\mathrm{B}_{\mathrm{u}}$ manifold - introducing artificial quasidegeneracy between the $\mathrm{B}_{\mathrm{u}}$ states. This artifice arises due to the zeroth-order energetic near-equivalency between these states in the stateaveraged zeroth-order calculation, which causes the resulting wavefunctions to be configurationally less well-resolved. This is immediately identifiable not only in the overestimation of the $1 \mathrm{~B}_{\mathrm{u}}$ state that results but also in the analysis of the respective wavefunctions - the $2 \mathrm{~B}_{\mathrm{u}}$ state has a considerably enhanced transition dipole moment as a result of configurational mixing with $1 \mathrm{~B}_{\mathrm{u}}$. At larger active spaces, the enhanced static correlation of the $2 \mathrm{~B}_{\mathrm{u}}$ state stabilizes it at zeroth order such that it falls below the $1 \mathrm{~B}_{\mathrm{u}}$ state prior to the perturbative correction, leading to improved resolution of the covalent and ionic configurational natures of the $2 B_{u}$ and $1 B_{u}$ states, respectively. Yet at the $(20,20)$ complete- $\pi$ active space, $1 B_{u}$ configurational contamination with higher-lying dark states that approach near-resonance at zeroth order results in a perturbative over-stabilization of this state. Thus, it is important to 
compare large-active-space results for dynamically-correlated states with those from more compact active spaces, whereby configuration-state mixing is minimized.

The $2 \mathrm{~A}_{\mathrm{g}}$ dependence on active-space size follows the more general trend set by neurosporene at larger active spaces - monotonically decreasing with the increase of outlying $\pi$ orbitals included at zeroth order. At full $\pi$ electron correlation using the $(20,20)$ active space, the $2 \mathrm{~A}_{\mathrm{g}}$ state drops to its lowest excitation energy of $2.79 \mathrm{eV}-0.06 \mathrm{eV}$ above the most reliable computed $1 \mathrm{~B}_{\mathrm{u}}$ excitation energy of $2.73 \mathrm{eV}$. While the ordering of states is unchanged following the one-double-bond conjugation-length increase from neurosporene to spheroidene, and both the $2 \mathrm{~A}_{\mathrm{g}}$ and $1 \mathrm{~B}_{\mathrm{u}}$ states attain lower excitation energies at this larger conjugation length, the computed energy gap between the states decreases by $0.06 \mathrm{eV}$. Thus, subtler bond-lengthalternation reduction in spheroidene should lead to the very same point of energetic degeneracy, meaning that the spheroidene Franck-Condon geometry is closer to the conical intersection. This enhanced proximity should increase the rate of $1 \mathrm{~B}_{u}$ depopulation. The $2 \mathrm{~B}_{\mathrm{u}}$ and $3 \mathrm{~A}_{\mathrm{g}}$ dark excited states likewise are stabilized by enlarging the $\pi$ active space and attain lowest computed excitation energies of $3.43 \mathrm{eV}$ and $4.05 \mathrm{eV}$, respectively. These excitation energies remain well above the computed $1 \mathrm{~B}_{\mathrm{u}}$ excitation energy.

\section{$\underline{\beta-C a r o t e n e ~(N=11)}$}

$\beta$-carotene is unique in the s-cis orientation of its terminal double bonds due to the $\beta$-ionone ring functionalization at either end of the polyene chain. Thus, it must be considered as having an effective conjugation length that is nearly two double bonds lower than its actual conjugation length on account of its anomalous end-chain orientation. Adopting an effective conjugation length of 9.5 as opposed to 11 , the most accurate computed $1 \mathrm{~B}_{\mathrm{u}}$ excitation energy of $2.76 \mathrm{eV}$ (using the $(16,16)$ active space) places the $\beta$-carotene absorption peak between those of 
neurosporene and spheroidene, as anticipated from the experimental literature. Given a lowest computed $2 \mathrm{~A}_{\mathrm{g}}$ excitation energy of $2.84 \mathrm{eV}$, the $1 \mathrm{~B}_{\mathrm{u}}-2 \mathrm{~A}_{\mathrm{g}}$ energy gap is $0.08 \mathrm{eV}$-slightly larger than that computed for spheroidene. Again, using effective conjugation length arguments, it can be reasoned that the intermediate $\mathrm{N}_{\text {effective }}=9.5$ for $\beta$-carotene renders the relative $2 \mathrm{Ag}_{\mathrm{g}}$ stabilization with respect to the conjugation-length increase from neurosporene $\left(\mathrm{N}_{\text {effective }}=9\right)$ lower than that incurred for spheroidene $\left(\mathrm{N}_{\text {effective }}=10\right)$. The $2 \mathrm{~A}_{\mathrm{g}}$ state is more stabilized by increased effective conjugation length than the $1 \mathrm{~B}_{\mathrm{u}}$ state, since the greater effective conjugation further delocalizes the excited states and more strongly supports the multi-excitation (correlatedtriplet-pair) electron correlation comprising the predominant $2 \mathrm{~A}_{\mathrm{g}}$ electron configuration.

At larger active spaces, the $2 \mathrm{~B}_{\mathrm{u}}$ and $3 \mathrm{~A}_{\mathrm{g}}$ states achieve their lowest excitation energies of 3.59 and $4.18 \mathrm{eV}$, respectively, which again constitute intermediate excitation energies with respect to neurosporene and spheroidene. The increased $2 \mathrm{~B}_{u}$ excitation energy at the complete- $\pi$ active space can be explained by the relative lack of dynamic-correlation stabilization that is itself attributable to a better variational initial guess for this excited state. The lower $3.59-\mathrm{eV}$ excitation energy at the smaller $(20,20)$ active space thus is more indicative of the expected excitation energy at the (fully variational) full configuration-interaction limit. On the other hand, the $3 \mathrm{~A}_{\mathrm{g}}$ state is better described variationally at the complete- $\pi(22,22)$ active space and is similarly stabilized perturbatively, resulting in a lower second-order excitation energy. As expected, the energy gap between these dark intermediate states and the $1 \mathrm{~B}_{\mathrm{u}}$ bright state is larger than that for spheroidene.

\section{Lycopene ( $\mathbf{N = 1 1 )}$}

Unlike $\beta$-carotene, lycopene has an all-trans arrangement of conjugated double bonds. Lycopene thus has an effective conjugation length $\left(\mathrm{N}_{\text {effective }}=11\right)$ that is over one double bond 
larger than that for $\beta$-carotene even though the two carotenoids have the same total number of conjugated double bonds. Because of its greater effective conjugation length, lycopene features lower-lying dark- and bright-state excitation energies - most accurately computed to be $2.66 \mathrm{eV}$ $(14,14)$ for $1 \mathrm{~B}_{\mathrm{u}}$ and $2.69 \mathrm{eV}(22,22)$ for $2 \mathrm{~A}_{\mathrm{g}}$-and a lower energy gap between $1 \mathrm{~B}_{\mathrm{u}}$ and $2 \mathrm{~A}_{\mathrm{g}}$ of $0.03 \mathrm{eV}$. The $2 \mathrm{~B}_{\mathrm{u}}$ and $3 \mathrm{~A}_{\mathrm{g}}$ excitation energies also appear lower at the complete- $\pi$ active space: $3.25 \mathrm{eV}$ and $3.87 \mathrm{eV}$, respectively. While configuration-state mixing again is apparent most clearly at the smaller $(10,10)$ active space, the larger active spaces feature well-resolved $1 \mathrm{~B}_{\mathrm{u}}$ and $2 \mathrm{~B}_{\mathrm{u}}$ wavefunctions, albeit outlying orbital correlation in the larger active spaces again leads to a perturbative over-correction of the $1 \mathrm{~B}_{\mathrm{u}}$ excitation energy. What is most important, however, is to compare lycopene to another carotenoid with an equivalent effective conjugation length to distinguish all-trans carotenoids from those with s-cis double-bond orientations. For this reason, results for the carotenoid rhodopin glucoside $\left(\mathrm{N}_{\text {effective }}=11\right)$ are furnished below-the results further signifying that excitation energies in hydrocarbon carotenoids are dictated not necessarily by variable functionalization, but rather by varying effective conjugation lengths. Consider the computed lycopene $2 \mathrm{~A}_{\mathrm{g}}$ excitation energy of $\mathbf{2 . 6 9} \mathrm{eV}$ at the complete- $\pi(22,22)$ active space:

\begin{tabular}{|l|l|l|l|l|l|l|l|l|l|l|l|}
\hline St. & Mu. & $(4,4)$ & $(6,6)$ & $(8,8)$ & $(10,10)$ & $(12,12)$ & $(14,14)$ & $(16,16)$ & $(18,18)$ & $(20,20)$ & $(22,22)$ \\
\hline 1 & 1 & 3.22 & 3.30 & 3.19 & 2.92 & 2.98 & 3.02 & 2.77 & 2.95 & 2.83 & $\mathbf{2 . 7 0}$ \\
\hline 2 & 1 & 2.63 & 2.78 & 2.87 & 3.18 & 3.54 & 3.82 & 3.34 & 3.58 & 3.35 & \\
\hline 3 & 1 & & 4.25 & 3.96 & 3.16 & 2.69 & 2.59 & & 4.15 & 4.00 & \\
\hline 4 & 1 & & & 4.77 & 4.59 & 4.64 & 4.72 & & 4.30 & 4.20 & \\
\hline 5 & 1 & & & & 4.64 & 5.07 & 4.91 & & & & \\
\hline 6 & 1 & & & & & & 5.13 & & & & \\
\hline 7 & 1 & & & & & & 5.49 & & & & \\
\hline
\end{tabular}




\begin{tabular}{|l|l|l|l|l|l|l|l|l|l|l|l|}
\hline 1 & 3 & 1.56 & 1.60 & 1.59 & 1.49 & & 1.54 & & & & \\
\hline 2 & 3 & 2.68 & 2.71 & 2.55 & 2.28 & & 2.34 & & & & \\
\hline
\end{tabular}

The resulting rhodopin glucoside excitation energy of $2.70 \mathrm{eV}$ resulting from the complete- $\pi$ active-space expansion agrees exceptionally well with that computed for lycopene, indicating that the variable end-group functionalization has negligible bearing on the excitation energies. Results for the other excitation energies also compare favorably across all active spaces considered. As such, the particular carotenoids chosen for this study are not as important as the effective conjugation lengths they represent.

\section{$\underline{\text { Spirilloxanthin }(\mathrm{N}=13)}$}

The longest-chain carotenoid considered in this study, spirilloxanthin poses a unique computational challenge in computing its excited states at a complete- $\pi$ active space, since this $(26,26)$ orbital basis pushes against the active-space-size limit that can be treated by NEVPT2/DMRG under realistic memory thresholds. For this study, a reduction in the variational complexity for each wavefunction from bond dimension 1000 to bond dimension 500 was programmed following orbital optimization so as to get around the memory bottleneck. As this study concerns the relative energies of the ground and excited states, such a reduction should not affect the resulting excitation energies significantly due to a cancellation in the correlationenergy underestimation between the ground and excited states assessed. Moreover, since stateaveraged DMRG-SCF orbital optimization proceeded with the normal bond dimension (M) of 1000 , it is straightforward to consider the effect of bond-dimension reduction on the zeroth-order excitation energies. As revealed in the below table, not only is the zeroth-order excitation energy effectively unchanged by the change in bond dimension at the CI/PT2 level, but also the total 
energies are effectively the same-providing assurance that the nature of the computed excited states and, in turn, their excitation energies, are unaffected.

\begin{tabular}{|l|l|l|l|l|}
\hline State & $\mathrm{M}=1000$ & $\mathrm{M}=500$ & $\mathrm{E}(1000)-\mathrm{E}(500)$ & $\mathrm{E}_{\text {rel }}(\mathrm{eV})$ \\
\hline $1 \mathrm{~A}_{\mathrm{g}}$ & -1775.3642 & -1775.3642 & $-3.10301 \mathrm{E}-08$ & 3.02 \\
\hline $2 \mathrm{~A}_{\mathrm{g}}$ & -1775.2531 & -1775.2531 & $8.9868 \mathrm{E}-07$ & 3.02 \\
\hline
\end{tabular}

The relative energies are unchanged with respect to bond dimension, since the total energies of the states themselves (in units of hartrees in the table) are unchanged.

The resulting trustworthy $2 \mathrm{~A}_{\mathrm{g}}$ excitation energies at the largest active spaces employed are lower than those computed at smaller active spaces with the normal variational bond dimension applied-reaching as low as $2.52 \mathrm{eV}$, or $0.17 \mathrm{eV}$ below that of the lycopene $2 \mathrm{~A}_{\mathrm{g}}$ state. Likewise, the $1 \mathrm{~B}_{\mathrm{u}}$ excitation energy is lowered to $2.51 \mathrm{eV}$ - the $0.15-\mathrm{eV}$ difference with respect to the lycopene $1 \mathrm{~B}_{\mathrm{u}}$ excitation energy reflecting the $\mathrm{N}_{\text {effective }}$ increase of two conjugated double bonds (from 11 to 13 ). The resulting energy gap between $2 \mathrm{~A}_{\mathrm{g}}$ and $1 \mathrm{~B}_{\mathrm{u}}$ is lowered still to the point that $2 \mathrm{~A}_{\mathrm{g}}$ and $1 \mathrm{~B}_{\mathrm{u}}$ are energetically indistinguishable at the effective conjugation length represented by spirilloxanthin — suggesting that the Franck-Condon geometry is the conicalintersection geometry. Thus, $1 \mathrm{~B}_{\mathrm{u}}$ depopulation triggered by internal conversion to $2 \mathrm{~A}_{\mathrm{g}}$ should be most efficient in spirilloxanthin. Moreover, the $2 \mathrm{~B}_{\mathrm{u}}$ and $3 \mathrm{~A}_{\mathrm{g}}$ excitation energies continue to decrease at the largest active spaces employed, signifying that these states pull closer to the photoexcited state as the effective conjugation length is increased along the hydrocarbon carotenoid series. Nonetheless, the energy gap between these so-called "dark intermediate states" and the photoexcited state is much vaster than that between $1 \mathrm{~B}_{\mathrm{u}}$ and $2 \mathrm{~A}_{\mathrm{g}}$ (negligible), suggesting that no dark intermediate state bridge must be invoked to explain the exceptionallyefficient and ultrafast depopulation of the bright state in carotenoid photophysics. 


\section{The Effect of Polarizable Continuum (PCM) Solvation on Carotenoid Excited States}

The effect of PCM solvation on carotenoid excitation energies was isolated by comparing MRPT calculations of vertical absorption energies between the ORCA package with PCM solvation and the PySCF package without PCM solvation. $\beta$-carotene was evaluated at the NEVPT2/CASSCF $(4,4)$ level under a tetrachloromethane solvent continuum and at the NEVPT2/DMRG(4,4)-SCF level in vacuo using the same geometry optimized under $\mathrm{CCl}_{4} \mathrm{PCM}$ solvation. As CAS/DMRG are expected to yield equivalent results at the standard $\mathrm{M}=1000$ bond dimension utilized, any changes in the excitation energies were attributed to the invocation of a polarizable continuum solvent interacting self-consistently with the state-averaged wavefunction computed at zeroth order. Our results indicate that the interaction with this low-dielectricconstant solvent has a negligible impact on the computed excitation energies, as documented in the below table:

\begin{tabular}{|l|l|l|l|}
\hline State & ORCA $\mathrm{E}_{\text {rel }}(\mathrm{eV})$ & PySCF $\mathrm{E}_{\text {rel }}(\mathrm{eV})$ & Difference $(\mathrm{eV})$ \\
\hline $2 \mathrm{~A}_{\mathrm{g}}$ & 3.33 & 3.35 & 0.02 \\
\hline${ }^{1 \mathrm{~B}_{\mathrm{u}}}$ & 2.69 & 2.73 & 0.04 \\
\hline${ }^{3} \mathrm{~B}_{\mathrm{u}}$ & 1.62 & 1.61 & 0.01 \\
\hline${ }^{3} \mathrm{~A}_{\mathrm{g}}$ & 2.79 & 2.80 & 0.01 \\
\hline
\end{tabular}

Solvatochromism is shown here to be negligible for $\mathrm{CCl}_{4}$ - the interaction with the bright $1 \mathrm{~B}_{\mathrm{u}}$ state is insufficiently large to trigger a large difference with respect to the in vacuo calculation. Such a comparison reveals that the impact of solvatochromism appears appreciably only for solvents with large dielectric constants as assessed in this study. Under these solvent conditions, the electronic interactions between the $1 \mathrm{~B}_{\mathrm{u}}$ state and the polarizable continuum along with the 
nuclear reorganization induced by solvent reorientation both have significant impacts on the vertical bright-state absorption and emission energies, respectively (Figure S1).
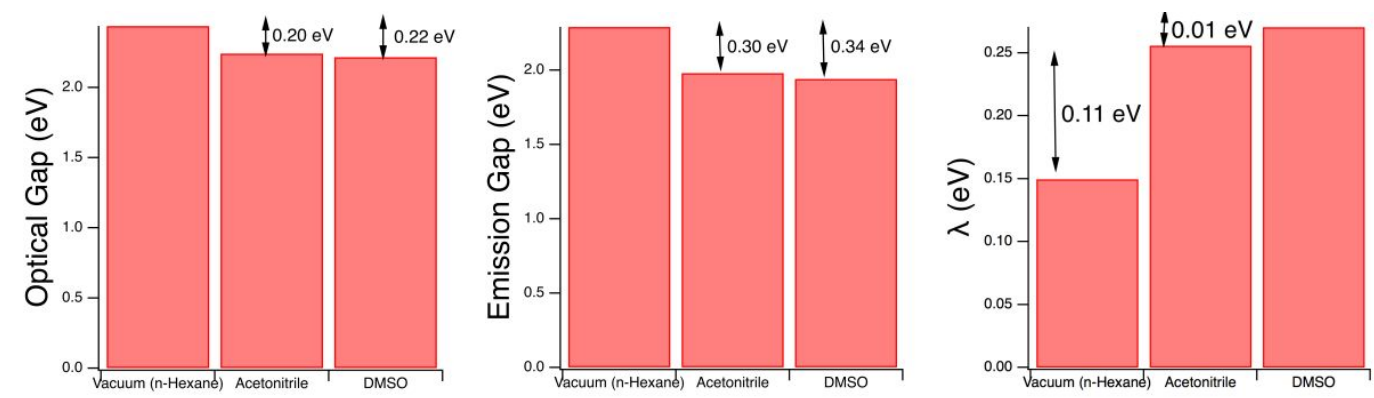

Figure S1. Solvatochromic shifts in absorption and emission, along with Stokes shifts for the $1 \mathrm{~B}_{\mathrm{u}}$ state of spheroidene computed in vacuo and under $\mathrm{ACN} / \mathrm{DMSO}$ solvation using statespecific PCM solvation and time-dependent density functional theory with the Tamm-Dancoff Approximation calculated using Gaussian 16. As the $1 \mathrm{~B}_{\mathrm{u}}$ state is single-reference in nature, the computed excitation energies, and shifts therein, are reasonable.

While $1 \mathrm{~B}_{\mathrm{u}}$ solvatochromism leads to its stabilization in the presence of polarizable continua with larger dielectric constants, the $2 \mathrm{~A}_{\mathrm{g}}$ state is concomitantly stabilized by nuclear reorganization around the enhanced dipole moment in the $1 \mathrm{~B}_{\mathrm{u}}$ state. Thus, following orientational solvent relaxation, the $2 \mathrm{~A}_{\mathrm{g}}$ state is stabilized by the reduction in effective conjugation (bond-lengthalternation reduction), as mentioned in the manuscript. This stabilization is apparent by considering simply the geometric change in the bright state of spheroidene following nuclear reorganization in ACN/DMSO compared to vacuum - a further elongation of the carbon-carbon double bond following nuclear reorganization pushes the $2 \mathrm{~A}_{\mathrm{g}}$ state closer to its minimum-energy geometry and thus stabilizes it (Figure S2). 


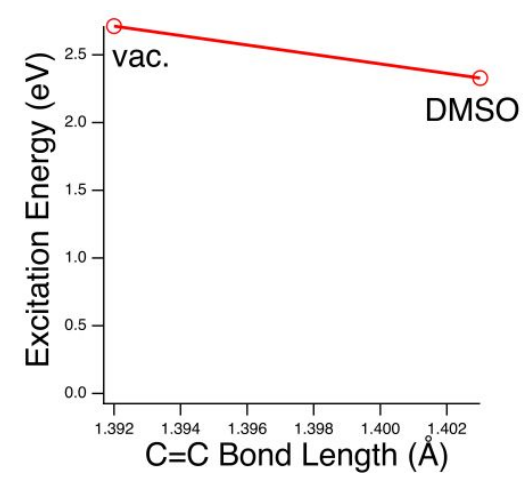

Figure S2. Stabilization of the $2 \mathrm{~A}_{\mathrm{g}}$ state as computed at the NEVPT2/DMRG(4,4)-SCF level with PySCF from the optimized $1 \mathrm{~B}_{\mathrm{u}}$ state geometries using PCM solvation with Gaussian 16. This stabilization is a purely geometric effect stemming from enhanced bright-state nuclear reorganization in the face of stronger solvent response - the solvatochromic shift of the dark state is negligible on account of its marginal ground-state-like dipole moment. To confirm the expected negligibility of $2 \mathrm{~A}_{\mathrm{g}}$ solvatochromism on theoretical grounds, MRPT calculations were performed in DMSO solvent using $O R C A$ on the $1 \mathrm{~A}_{\mathrm{g}}$ optimized spheroidene ground-state geometry computed using a Gaussian 16 DMSO PCM solvent with DFT(B3LYP). Including PCM solvation in the state-averaged $\operatorname{CASSCF}(4,4)$ electronic-structure calculation negligibly changed the $2 \mathrm{~A}_{\mathrm{g}}$ excitation energy relative to the state-averaged $\mathrm{DMRG}(4,4)-\mathrm{SCF}$ calculation performed in vacuo using the same spheroidene $1 \mathrm{~A}_{\mathrm{g}}$ geometry:

\begin{tabular}{|l|l|l|l|}
\hline State & DMSO & Gas & Difference \\
\hline $1 \mathrm{~A}_{\mathrm{g}}\left(\mathrm{E}_{\text {total }}\right)$ & -1662.385251 hartree & -1662.357722 hartree & 0.027529048 hartree \\
\hline $2 \mathrm{~A}_{\mathrm{g}}\left(\mathrm{E}_{\text {excitation }}\right)$ & $3.97 \mathrm{eV}$ & $3.97 \mathrm{eV}$ & $0 \mathrm{eV}$ \\
\hline
\end{tabular}

This result further suggests that the solvatochromism in carotenoid excited states is exclusive to the $1 \mathrm{~B}_{\mathrm{u}}$ bright state due to the similarly small $1 \mathrm{~A}_{\mathrm{g}}$ and dark excited-state solvent interactions. The $2 \mathrm{~A}_{\mathrm{g}}$ state is stabilized only by $1 \mathrm{~B}_{\mathrm{u}}$ nuclear reorganization around the continuum solvent. 


\section{Ground-State Geometric Discrepancies between CASSCF and DFT}

As the equilibrium configuration of a closed-shell ground state at its optimized geometry is expected to be single-reference in nature-weighted strongly by the Hartree-Fock configuration in a multi-configurational sense - the need to employ a multireference ground-state geometry optimization method is questionable at face value. Moreover, our calculations suggest that geometric optimization of the carotenoid $1 \mathrm{~A}_{\mathrm{g}}$ state with $\operatorname{CASSCF}(4,4)$ leads to less accurate (larger) bond-length alternation than that computed using DFT with the B3LYP functional (both optimizations used the cc-pVDZ basis set). Physically, the CASSCF optimization localizes the electron correlation of the ground state to within the basis of the four frontier molecular orbitals closest to the Fermi level (HOMO-1, HOMO, LUMO and LUMO+1). This many-body localization triggered by static electron correlation is not counterbalanced by dynamic correlation that delocalizes electrons across the conjugated chain through $\sigma, \pi$ mixing and, in turn, supports lower bond-length alternation. Because this dynamic correlation is treated approximately through the B3LYP functional and Hartree-Fock exchange included therein, DFT delocalizes the ground-state electronic structure-leading to a ground-state geometry that yields more reasonable excitation energies when interrogated using strong-correlation MRPT methods. As seen in Figure S3, the geometry acquired from a purely static-correlation treatment results in erroneously high absorption peak energies computed at the NEVPT2/DMRG(6,6)-SCF level, immediately signaling that the ground-state over-localization produces a flawed structure. 


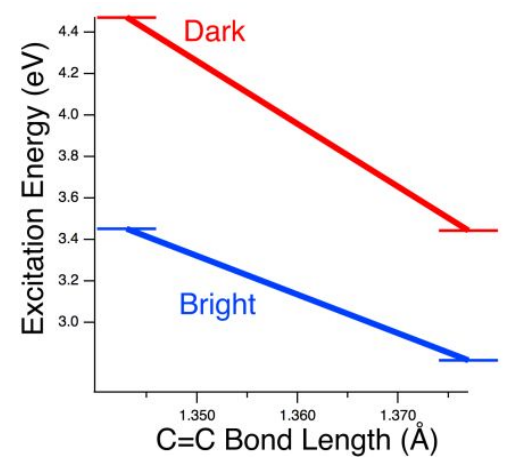

Figure $\mathrm{S} 3$. Excitation energies of the bright $1 \mathrm{~B}_{\mathrm{u}}$ and dark $2 \mathrm{~A}_{\mathrm{g}}$ excited states of spheroidene computed at the NEVPT2/DMRG(6,6)-SCF level with respect to the CASSCF $(4,4)$-optimized (left) and DFT(B3LYP)-optimized (right) geometries. The bright-state excitation energy and $1 \mathrm{~B}_{\mathrm{u}} / 2 \mathrm{~A}_{\mathrm{g}}$ energy gap are more reasonable when using the DFT optimized geometry.

\section{Additional Absorbance Data for Carotenoids with Conjugation Length 11}

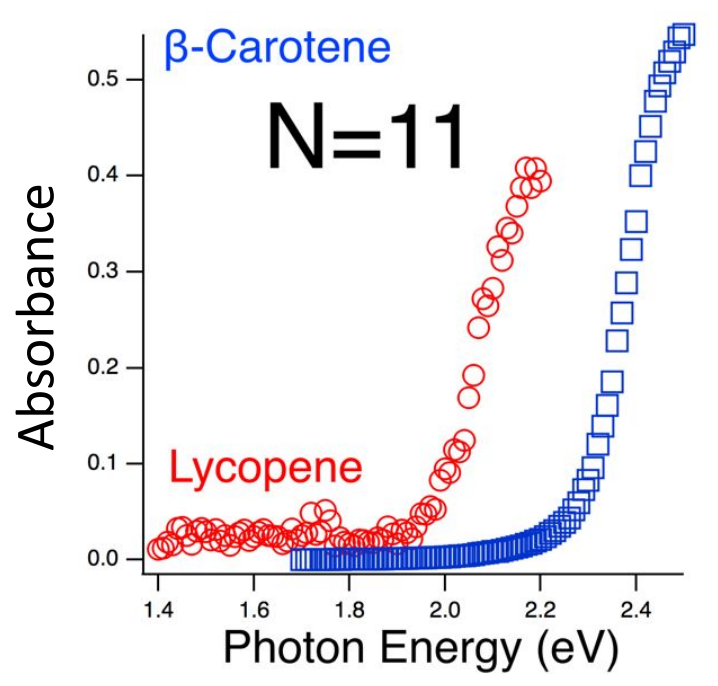

Figure S4. PDS data for the long-chain carotenoids with conjugation length $\mathrm{N}=11$. 


\section{Carotenoid Conical Intersections}

Table S2. Spheroidene Excitation Energies at its Optimized In Vacuo $1 \mathrm{~B}_{\mathrm{u}}$ Geometry With Respect to Active Space Size.

\begin{tabular}{|c|c|c|c|c|c|c|c|c|c|c|}
\hline St. & Mult. & $(4,4)$ & $(6,6)$ & $(8,8)$ & $(10,10)$ & $(12,12)$ & $(14,14)$ & $(16,16)$ & $(18,18)$ & $(20,20)$ \\
\hline 1 & 1 & $2.75^{b}$ & $2.79^{b}$ & $2.89^{b}$ & $2.77^{b}$ & $2.72^{b}$ & $2.57^{b}$ & $2.48^{b}$ & $2.41^{b}$ & $2.32^{b}$ \\
\hline 2 & 1 & ${\underline{2.40^{a}}}^{\mathrm{a}}$ & $2.42^{\mathrm{a}}$ & 4.39 & 4.02 & 3.67 & 3.53 & 3.34 & 3.20 & 3.05 \\
\hline 3 & 1 & & 4.52 & $2.38^{\mathrm{a}}$ & $2.46^{\mathrm{a}}$ & 4.44 & 4.36 & 4.11 & & 3.71 \\
\hline 4 & 1 & & & & & & 4.41 & 4.25 & & 3.88 \\
\hline 5 & 1 & & & & & & & 4.71 & & 4.40 \\
\hline 6 & 1 & & & & & & & & & \\
\hline 1 & 3 & 1.31 & 1.31 & & & & & & & \\
\hline 2 & 3 & 2.36 & 2.39 & & & & & & & \\
\hline
\end{tabular}

While the best variational initial guess for the $1 \mathrm{~B}_{\mathrm{u}}$ state is the $(4,4)$ calculation leading to the most trustworthy $1 \mathrm{~B}_{\mathrm{u}}$ emission energy of $2.40 \mathrm{eV}$, the $2 \mathrm{~A}_{\mathrm{g}}$ complete- $\pi$ active-space excitation energy of $2.32 \mathrm{eV}$ signifies that a conical intersection leading to the energetic reordering of $1 \mathrm{~B}_{\mathrm{u}}$ and $2 \mathrm{~A}_{\mathrm{g}}$ exists along the $1 \mathrm{~B}_{\mathrm{u}}$ geometry optimization pathway from the ground-state structure. While the $2 \mathrm{~A}_{\mathrm{g}}-1 \mathrm{~B}_{\mathrm{u}}$ energy gap is positive at the Franck-Condon geometry by $0.06 \mathrm{eV}$, it is computed to be negative at the fully-reorganized bright-state geometry by $0.08 \mathrm{eV}$, thereby indicating a $0.14-\mathrm{eV}$ relative stabilization of $2 \mathrm{~A}_{\mathrm{g}}$ compared to $1 \mathrm{~B}_{\mathrm{u}}$ triggered by nuclear reorganization along the $1 \mathrm{~B}_{\mathrm{u}}$ potential energy surface. Such a small relative stabilization suggests that the $1 \mathrm{~B}_{\mathrm{u}}$ and $2 \mathrm{~A}_{\mathrm{g}}$ states remain closely coupled nonadiabatically along the carbon- 
carbon stretching reaction coordinate - the Franck-Condon-active totally-symmetric vibrational modes mediating energetic resonance between $1 \mathrm{~B}_{\mathrm{u}}$ and $2 \mathrm{~A}_{\mathrm{g}}$. Such Raman-active modes can be described as gradient-difference vectors tuning the $1 \mathrm{~B}_{\mathrm{u}}$ and $2 \mathrm{~A}_{\mathrm{g}}$ relative energies. On the other hand, this spectator mode must be accompanied by symmetry-breaking coupling modes along the branching plane: two nuclear vibrational modes that mediate population transfer from $1 \mathrm{~B}_{\mathrm{u}}$ to $2 \mathrm{~A}_{\mathrm{g}}$ according to the following group-theory description of vibronic coupling:

$$
2 A_{g}=1 B_{u} \otimes b_{u}
$$

This total-symmetry-conserving coupling between two antisymmetric electronic states $\left(2 \mathrm{~A}_{\mathrm{g}}\right.$ and $\left.1 \mathrm{~B}_{\mathrm{u}}\right)$ is mediated by a non-totally-symmetric vibrational mode $\left(\mathrm{b}_{\mathrm{u}}\right)$ that, by definition, is not Franck-Condon active. This is because Franck-Condon-active modes must be totally symmetric to preserve the anti-symmetry between the electronic states involved in the optical transition:

$$
1 A_{g} \rightarrow 1 B_{u} \otimes a_{g}
$$

As a result, it is well known that Franck-Condon-active high-frequency carbon-carbon stretching modes drive wavepacket evolution to the geometric minimum of the bright $1 \mathrm{~B}_{\mathrm{u}}$ electronic state. As the wavepacket evolves along these high-frequency modes with periods of $\sim 10 \mathrm{fs}$, subsequent intramolecular vibrational redistribution (IVR) - induced by thermal relaxation in the $1 \mathrm{~B}_{\mathrm{u}}$ state as vibrational energy is dissipated into the bath - leads to the population of low-frequency torsional modes that disrupt the effective $\mathrm{C}_{2 \mathrm{~h}}$ point-group symmetry of the carotenoid polyene backbone. Thus, it is only following IVR that the $1 \mathrm{~B}_{\mathrm{u}}$ state population is transferred to the $2 \mathrm{~A}_{\mathrm{g}}$ state through coupling to non-totally-symmetric nuclear vibrations - a process that appears to take $\sim 100 \mathrm{fs}$ as detailed in the literature. It therefore seems reasonable to infer that the "hot" $2 \mathrm{~A}_{\mathrm{g}}$ state transient spectral signature appearing after the first 100 fs following optical excitation is the 
manifestation of IVR-generated population transfer from $1 \mathrm{~B}_{\mathrm{u}}$ to $2 \mathrm{~A}_{\mathrm{g}}$ through the conical intersection.

Discrepancies between the $1 \mathrm{~B}_{\mathrm{u}}$ and $2 \mathrm{~A}_{\mathrm{g}}$ minimum-energy geometries—offering physical insight into the structural reorganization and vibrational activity mediating population transfersuggest that torsional distortion accompanies reorganization in the $2 \mathrm{~A}_{\mathrm{g}}$ potential energy surface. The floppy end substituents of carotenoids are most susceptible to torsional distortion, so the geometric minima of the $1 \mathrm{~A}_{\mathrm{g}}, 1 \mathrm{~B}_{\mathrm{u}}$ and $2 \mathrm{~A}_{\mathrm{g}}$ states were compared on the basis of dihedral angles at the chain ends. As displayed in Figure S5, slight torsional distortion is apparent from the $1 \mathrm{~B}_{\mathrm{u}}$ to $2 \mathrm{~A}_{\mathrm{g}}$ geometries, suggesting that out-of-plane symmetry-breaking torsional modes are indeed active over the course of the dynamics connecting the lowest-lying dark and bright states.

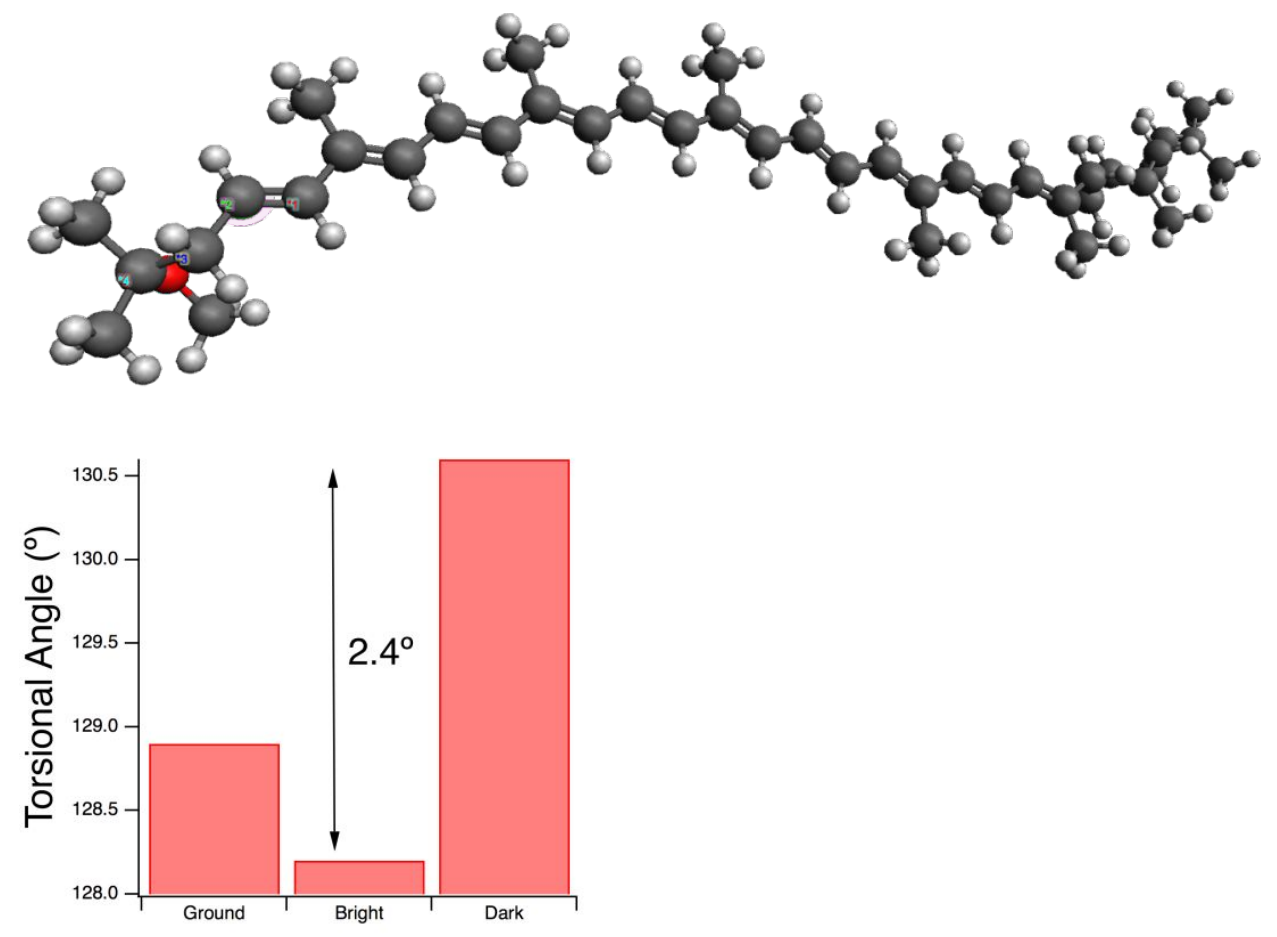

Figure S5. C-C-C-C torsional angle at the hydroxide end group of spheroidene (dihedral angle highlighted above) for the $1 \mathrm{~A}_{\mathrm{g}}$ (ground), $1 \mathrm{~B}_{\mathrm{u}}$ (bright) and $2 \mathrm{~A}_{\mathrm{g}}$ (dark) minimum-energy geometries. The difference in torsional angle between the $1 \mathrm{~B}_{u}$ and $2 \mathrm{~A}_{\mathrm{g}}$ geometries is noted. 
This working mechanism of IVR-driven population transfer between $1 \mathrm{~B}_{\mathrm{u}}$ and $2 \mathrm{~A}_{\mathrm{g}}$ states-with Franck-Condon-active tuning modes and non-totally-symmetric coupling modesmay explain the ultrafast (sub-ps) depopulation of the photoexcited state. This ultrafast depopulation, however, may appear at first glance to be detrimental to carotenoid-to(bacterio)chlorophyll energy transfer on account of the weaker dipole-dipole coupling to the dark $2 \mathrm{~A}_{\mathrm{g}}$ state. Nonetheless, the dichotomy of bright and dark states sharing excited electronic population is illustrative of the varying roles played by carotenoids in photosynthesis. Not only do carotenoids robustly transfer excitation energy to (bacterio)chlorophyll to initiate the chemistry of photosynthesis (photoinduced electron transfer), but also carotenoids serve to down-convert and dissipate excess electronic energy as heat. The population of the $2 \mathrm{~A}_{\mathrm{g}}$ dark state, by virtue of the corresponding fluorescence quenching (suppressed oscillator strength) and enhanced vibronic coupling for nonradiative decay to $1 \mathrm{~A}_{\mathrm{g}}$, likely serves to activate the carotenoid photoprotective mechanism. That is, provided that energy transfer from carotenoid to (bacterio)chlorophyll is not completed prior to $1 \mathrm{~B}_{\mathrm{u}}$ bright-state depopulation, $2 \mathrm{~A}_{\mathrm{g}}$ nonradiative internal conversion to the ground state — or, albeit less likely, singlet fission to the ${ }^{3} \mathrm{~B}_{\mathrm{u}}$ lowestlying triplet state (shown here to be thermodynamically favored) — dumps the excess energy. Moreover, by virtue of the large bond-length-alternation displacement along the $2 \mathrm{~A}_{\mathrm{g}}$ potential energy surface, resonance with the $\mathrm{Q}_{\mathrm{x}}$ and $\mathrm{Q}_{\mathrm{y}}$ states can be expected along the reorganization pathway to the dark-state geometric minimum. As the $2 \mathrm{~A}_{\mathrm{g}}$ state possesses non-negligible, albeit small, oscillator strength at its minimum-energy geometry, its population should not entirely shut off the energy-transfer pathway, especially considering the resonance enhancement that likely would manifest as the "hot" $2 \mathrm{~A}_{\mathrm{g}}$ state thermally relaxes. Thus, a duality of carotenoid photophysical functions is preserved by population transfer to the dark state. 


\section{Carotenoid Nonadiabatic Dynamics}

To test our assertion that a bridgeless binary system of bright $1 \mathrm{~B}_{\mathrm{u}}$ and dark $2 \mathrm{~A}_{\mathrm{g}}$ explains the observed ultrafast population of a dark excited state, we report here nonadiabatic dynamics simulations carried out in vacuo on an ensemble of conformations around the equilibrium geometry of a truncated peridinin model carotenoid structure (Figure S6).

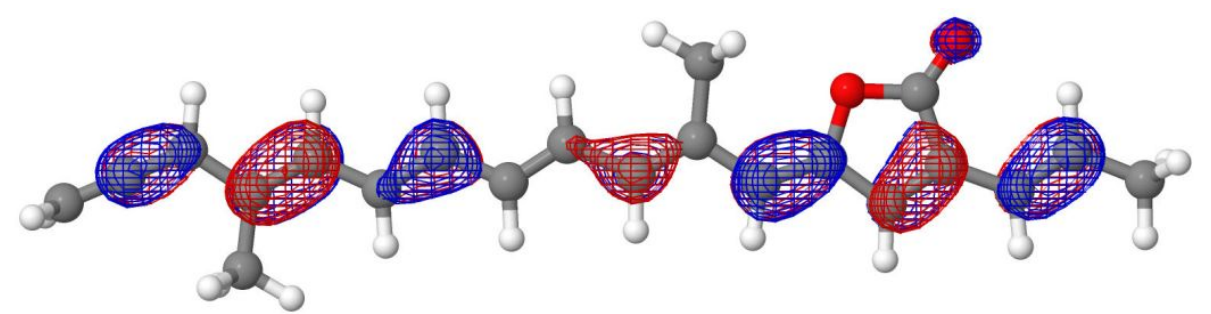

Figure S6. HOMO of the truncated peridinin model carotenoid structure employed during the nonadiabatic dynamics, generated by considering the functionalization within the conjugated chain of peridinin and eliminating the non-conjugated functionalization on either end. Unlike the hydrocarbon carotenoids discussed in this manuscript, peridinin is a carbonyl carotenoid with an allene tail and a lactone ring, yet it features the same $1 \mathrm{~B}_{\mathrm{u}}$ and $2 \mathrm{~A}_{\mathrm{g}}$ lowest-lying excited states. The choice of model carotenoid structure was made purely for numerical convenience — such a structure has only forty-five atoms, whereas the long-chain hydrocarbon carotenoids assessed in this manuscript have around one hundred atoms - and can be generalized to reflect the dynamics of all $1 \mathrm{D}$ linear chain molecules featuring dichotomous $1 \mathrm{~B}_{\mathrm{u}}$ and $2 \mathrm{~A}_{\mathrm{g}}$ states.

So that the bright and dark excited states at the ground-state geometry could be energetically proximal to one another in accordance with the NEVPT2/DMRG results in this study, a CASSCF $(4,4)$ optimized geometry constituted the equilibrium ground-state structure used for the generation of initial conditions and subsequent dynamics. As already discussed (vide supra), a CASSCF optimized geometry over-localizes double bond order due to the nondynamic electron correlation implemented in the geometry optimization. The dark state, in 
turn, is relatively destabilized by the over-localization such that it lies energetically close to, but nonetheless above, the bright state at the state-averaged CASSCF(4,4) level of theory (Table S3). Table S3. Bright- and dark-state excitation energies at the $\operatorname{CASSCF}(4,4)$ optimized geometry.

\begin{tabular}{|l|l|}
\hline $1 \mathrm{~B}_{\mathrm{u}}$ & $4.70 \mathrm{eV}$ \\
\hline $2 \mathrm{~A}_{\mathrm{g}}$ & $5.38 \mathrm{eV}$ \\
\hline
\end{tabular}

While these excitation energies clearly are overestimated, the excitation-energy difference between the states at the Franck-Condon geometry is qualitatively correct, and this is what we are concerned with in the context of nonadiabatic dynamics and population transfer between the excited states. Thus, the $\operatorname{CASSCF}(4,4)$ optimized geometry was used as input for nonadiabatic dynamics using three-singlet-state-averaged $\mathrm{CASSCF}(4,4)$ electronic-structure calculations with resolution-of-the-identity Cholesky-decomposed (RICD) two-electron repulsion integrals and analytical gradients - representing a significant dimensionality reduction in configuration space and affording computational tractability over the timescale of interest (more than $50 \mathrm{fs}$ ). Such simulations were performed using the SHARC package ${ }^{1-3}$ interfaced with OpenMolcas $18^{4-6}$ over an ensemble of initial conditions extracted from a Wigner distribution at $300 \mathrm{~K}$. The resulting optical spectrum encompassing the excitation energies and oscillator strengths for the two lowest excited states corresponding to all trajectories is displayed in Figure S7.

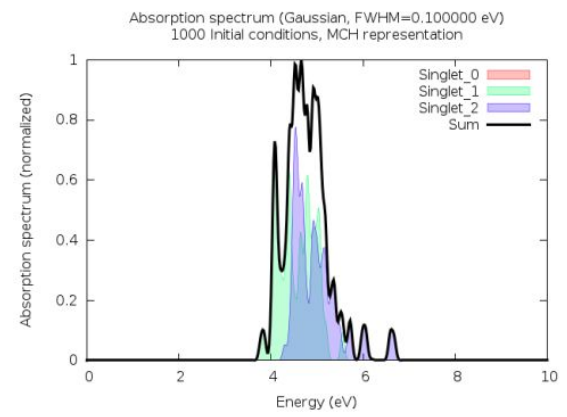

Figure S7. Peridinin absorption spectrum encompassing $\mathrm{S}_{1} / \mathrm{S}_{2}$ with Gaussian broadening. 
The absorption spectrum indicates that the lowest-lying excited states of peridinin are admixtures of one another at the $\operatorname{CASSCF}(4,4)$ level. This configurational mixing is the result of excitedstate quasidegeneracy at this level of theory (vide supra) and is desirable for this nonadiabatic dynamics implementation, given that the objective is to discern the realization of a lowest-lying dark state from an initial pair of closely-coupled wavefunctions. This close coupling, manifested in the configurational mixing and overlapping signatures underlying the absorption spectrum in Figure S7, suggests that the photoexcited wavepacket simulated by the conformational ensemble is near the conical intersection seam, which should trigger short-time surface hopping.

We indeed observe short-time surface hopping within our launched trajectories, propagated at 0.5 -fs time steps, and uncover population transfer to a configurationally-distinct lowest-lying dark state on an ultrashort timescale of less than $100 \mathrm{fs}$, in agreement with experiment. The time-dependent electronic population within the ensemble of trajectories is depicted in Figure S8.

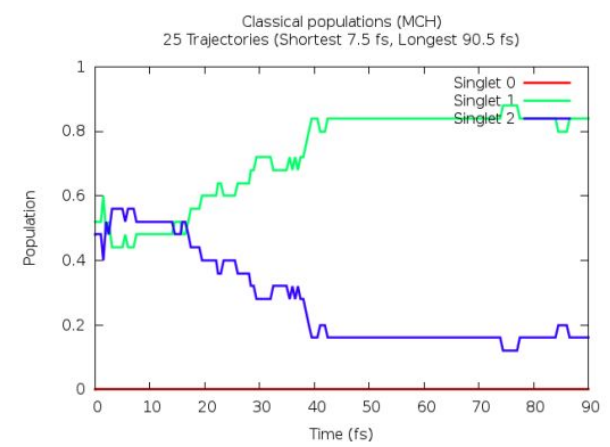

Figure S8. The time-dependent electronic population of the three simulated states. Initial population is equitably distributed between the closely-coupled configurationally-mixed states, yet nuclear reorganization in time induces population transfer from $S_{2}$ to $S_{1}$ within 50 fs. This population transfer coincides with the emergence of clearly distinguishable dark and bright 
character inherent to the states and the concomitant stabilization of the dark state relative to the bright state (Figure S9).
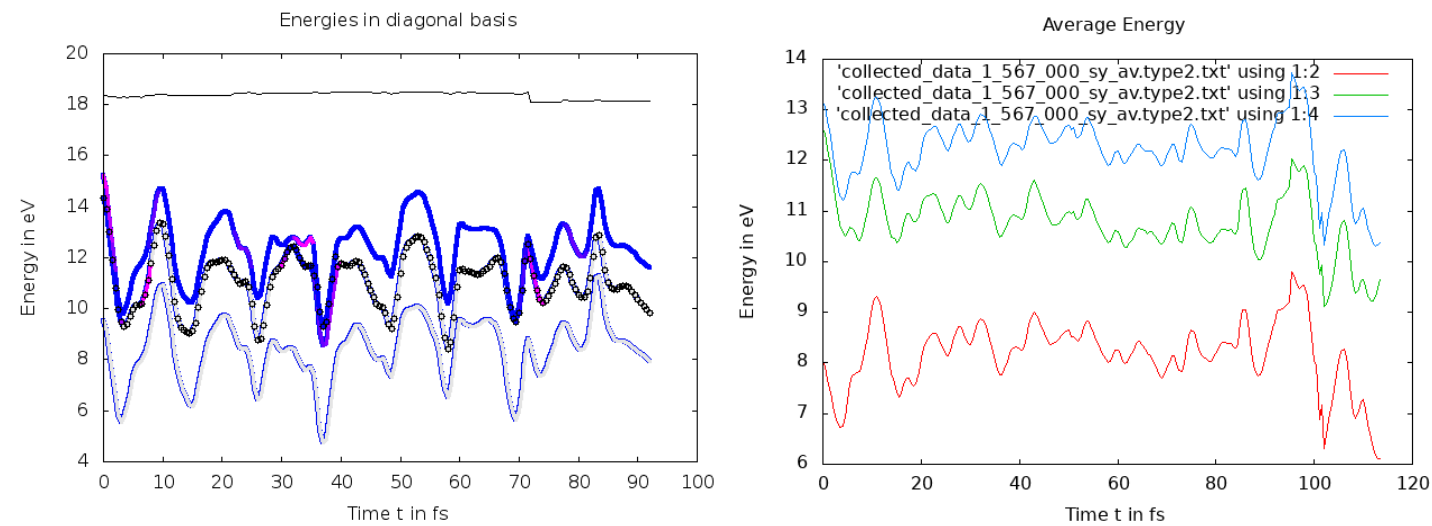

Figure S9. (Left) Potential energies of the three states included in the dynamics for a representative trajectory (top line represents total energy). Within each curve, bluer color represents high oscillator strength, or a bright state, whereas grayer color represents low oscillator strength, or a dark state. Open circles on a curve represent electronic population. The figure reveals the periodic oscillation of the curve corresponding to the period of a FranckCondon-active carbon-carbon stretching mode, the close coupling between two configurationally-mixed bright states at the start of the dynamics, the surface hopping between these states occurring at 35.5 and 39.0 fs and the late-time separation of the states energetically and configurationally. A lowest-lying dark state is shown to be populated at the tail end of the simulation (near $90 \mathrm{fs}$ ). (Right) Ensemble-averaged potential energies of the states at each time step of the dynamics. While the excited states are energetically proximal at early time steps, subsequent nuclear reorganization stabilizes the first singlet excited state more significantly and leads to the isolation of dark-state character on this state. 


\section{Relevant Optimized Geometries}

\section{$\underline{\text { Spheroidene }}$}

\section{1. $\mathrm{S}_{0}$ Geometry (B3LYP/cc-pVDZ):}

C $10.68929800 \quad 0.45020000-0.36454100$

C $12.00645800 \quad 0.82207800-0.32888800$

C $13.02068000-0.22463300-0.25375300$

C $14.35879100-0.05048300-0.22065100$

$\mathrm{H} 12.63236500-1.25076700-0.22562500$

C $9.528929001 .29691000-0.43750800$

$\mathrm{H} 10.48166200-0.62645000-0.33434500$

C $8.25252000 \quad 0.81139300-0.46835900$

$\mathrm{H} \quad 9.68262200 \quad 2.37806100-0.46936700$

C $7.034977001 .58828500-0.53985100$

$\mathrm{H} \quad 8.12085300-0.27689200-0.43587300$

C $5.83365200 \quad 0.91919600-0.56123100$

C $4.51299600 \quad 1.47205900-0.62685700$

$\mathrm{H} \quad 5.88345400 \quad-0.17574600-0.52288400$

C $3.38128700 \quad 0.70215100 \quad-0.64248100$

$\mathrm{H} \quad 4.41016000 \quad 2.55896900-0.66535800$

C $2.01908900 \quad 1.17469400 \quad-0.70502400$

$\mathrm{H} \quad 3.50696100-0.38655200-0.60339800$

C $1.00423900 \quad 0.24387100-0.71144200$

C $-0.40633200 \quad 0.47412700-0.76640600$

$\mathrm{H} \quad 1.30757700-0.80924700-0.66883400$

C $-1.33922000-0.53005600-0.76833500$

$\mathrm{H}-0.76938500 \quad 1.50591700 \quad-0.80905900$

C $-2.75145500-0.30208300-0.82246100$

$\mathrm{H}-0.97523900-1.56156400-0.72581900$

C $-3.76180700-1.23446800-0.82939700$

$\mathrm{H}-3.05669500 \quad 0.75054200 \quad-0.86330700$

C $-5.13116200-0.76599200-0.88970400$

C $-6.25404800-1.53779400-0.90459600$

$\mathrm{H}-5.25932500 \quad 0.32265500 \quad-0.92564400$

C $-7.59117000-0.98978700-0.96577900$

$\mathrm{H}-6.14861000-2.62470300-0.86555700$

C $-8.76867500-1.66672900-0.98689400$

$\mathrm{H}-7.64497100 \quad 0.10539500 \quad-0.99932700$

C $12.46728300 \quad 2.25698700 \quad-0.36156100$

$\mathrm{H} 13.06910100 \quad 2.49477900 \quad 0.53214100$

$\mathrm{H} 11.63527500 \quad 2.97049500-0.40505200$

$\mathrm{H} \quad 13.11422900 \quad 2.44154600-1.23647000$

C $7.14312900 \quad 3.09279000-0.58691700$

$\mathrm{H} \quad 6.16569800 \quad 3.58746600 \quad-0.64024300$

H $7.73071200 \quad 3.41703900-1.46265400$ 


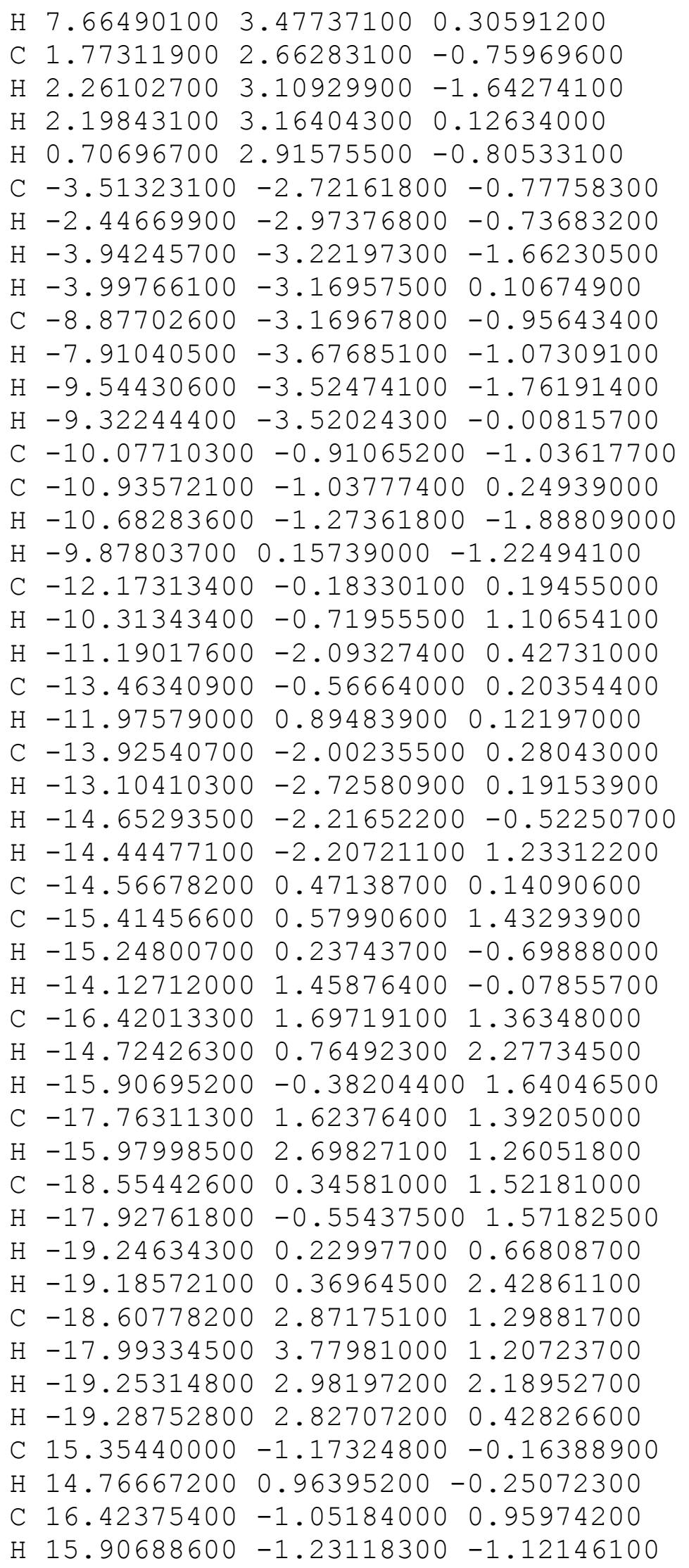



H $14.81999200-2.13321300-0.06900700$
C $17.25085000-2.34558800 \quad 1.02560500$
$\mathrm{H} \quad 16.61878400-3.23558900 \quad 1.16935700$
H $17.97223500-2.29472000 \quad 1.85614000$
H $17.81193000-2.49025200 \quad 0.08886500$
C $17.35482000 \quad 0.14062100 \quad 0.71406300$
$\begin{array}{lllll}0 & 15.82140400 & -0.74535200 & 2.23020600\end{array}$
$\mathrm{H} 18.11220200 \quad 0.19033600 \quad 1.51107400$
$\mathrm{H} 16.79305000 \quad 1.08580400 \quad 0.73232600$
$\mathrm{H} \quad 17.86898300 \quad 0.05048800 \quad-0.25545600$
C $14.93191300-1.69379800 \quad 2.78462300$
$\mathrm{H} \quad 14.56484600 \quad-1.25672500 \quad 3.72510700$
$\mathrm{H} \quad 15.42359200 \quad-2.65652200 \quad 3.02115600$
$\mathrm{H} 14.05901000-1.89441100 \quad 2.13641800$

\section{2. $\mathrm{S}_{2}$ Geometry (TDA/B3LYP/cc-pVDZ):}
C $10.63098500 \quad 0.58551000-0.26861600$
C $11.99881200 \quad 0.79848700-0.19629600$
C $12.87045100-0.34916000-0.30528500$
C $14.22927400-0.34178200-0.27092500$
$\mathrm{H} 12.36708100-1.31570300-0.43318400$
C $9.58116100 \quad 1.54157800-0.19109500$
H $10.31181500-0.45522600-0.40442100$
C $8.24873400 \quad 1.18145400-0.28080200$
$\mathrm{H} \quad 9.83428300 \quad 2.59536900-0.05726000$
C $7.11403400 \quad 2.04963100-0.21836600$
$\mathrm{H} \quad 8.02988300 \quad 0.11500500 \quad-0.41534800$
C $5.85497200 \quad 1.47264300-0.33307500$
C $4.57530900 \quad 2.09634200-0.30731200$
$\mathrm{H} \quad 5.84023100 \quad 0.38298700-0.46242900$
C $3.40975400 \quad 1.36311400-0.43683400$
$\mathrm{H} \quad 4.51337300 \quad 3.17909100-0.18288800$
C $2.06648700 \quad 1.85500300-0.43035800$
$\mathrm{H} \quad 3.51929700 \quad 0.27805700 \quad-0.55950300$
C $1.03695600 \quad 0.92998900 \quad-0.57727700$
C $-0.36360300 \quad 1.14742700-0.60644000$
$\mathrm{H} 1.34973700-0.11661600-0.68641800$
C $-1.28038200 \quad 0.11508100-0.76075100$
$\mathrm{H}-0.74943000 \quad 2.16621000-0.50429400$
C $-2.68437200 \quad 0.27990300 \quad-0.79651500$
$\mathrm{H}-0.87095600-0.89623700-0.86064800$
C $-3.66114600-0.70477100-0.94698300$
$\mathrm{H}-3.04828500 \quad 1.30925600-0.69266000$
C $-5.03823900-0.31605100-0.95561000$
C $-6.13029500-1.14570300-1.09084500$
$\mathrm{H}-5.23308000 \quad 0.75734500-0.84009200$ 


$\begin{array}{llll}\mathrm{C} & -7.48458300 & -0.67272000 & -1.08674600 \\ \mathrm{H} & -5.96333900 & -2.22034300 & -1.20127400 \\ \mathrm{C} & -8.63307300 & -1.40202000 & -1.22534100 \\ \mathrm{H} & -7.60177600 & 0.41067000 & -0.95486400 \\ \mathrm{C} & 12.60741100 & 2.16261100 & -0.01061900 \\ \mathrm{H} & 13.23579800 & 2.19253900 & 0.89626900 \\ \mathrm{H} & 11.85370600 & 2.95434300 & 0.07844600 \\ \mathrm{H} & 13.26543900 & 2.41983600 & -0.85906700 \\ \mathrm{C} & 7.32621600 & 3.53126000 & -0.03451600 \\ \mathrm{H} & 6.38134900 & 4.08776300 & 0.00084500 \\ \mathrm{H} & 7.92991900 & 3.95323100 & -0.85712300 \\ \mathrm{H} & 7.87176900 & 3.74304400 & 0.90177100 \\ \mathrm{C} & 1.83096300 & 3.33521700 & -0.26711900 \\ \mathrm{H} & 2.31953300 & 3.90984100 & -1.07428400 \\ \mathrm{H} & 2.25318600 & 3.70523500 & 0.68430900 \\ \mathrm{H} & 0.76439400 & 3.59342800 & -0.27728000 \\ \mathrm{C} & -3.32144900 & -2.16669900 & -1.10035100 \\ \mathrm{H} & -2.24115200 & -2.35745400 & -1.09556700 \\ \mathrm{H} & -3.72723700 & -2.56859000 & -2.04496400 \\ \mathrm{H}-3.76951500 & -2.76276500 & -0.28627800 \\ \mathrm{C} & -8.65182000 & -2.89483900 & -1.42430100 \\ \mathrm{H} & -7.68043100 & -3.29583800 & -1.74553300 \\ \mathrm{H}-9.40095600 & -3.17810300 & -2.18551500 \\ \mathrm{H}-8.93614500 & -3.42879300 & -0.49751300 \\ \mathrm{C} & -9.97711300 & -0.72117400 & -1.16018900 \\ \mathrm{C} & -10.82523200 & -1.10314800 & 0.08570400 \\ \mathrm{H}-10.57175600 & -0.97519900 & -2.05951900 \\ \mathrm{H} & -9.84010200 & 0.37324200 & -1.17145800 \\ \mathrm{C} & -12.11303400 & -0.32973100 & 0.15966900 \\ \mathrm{H}-10.21996400 & -0.88697300 & 0.98538700 \\ \mathrm{H}-11.01053700 & -2.18786700 & 0.09012500 \\ \mathrm{C} & -13.37700100 & -0.78448300 & 0.06810500 \\ \mathrm{H} & -16.10831100 & 2.08025400 & 1.62972500 \\ \mathrm{C}-18.52928000 & -0.43512400 & 1.42618000\end{array}$




$\begin{array}{llll}\mathrm{H} & -17.84652300 & -1.28973600 & 1.33041900 \\ \mathrm{H} & -19.20514800 & -0.44166600 & 0.55195500 \\ \mathrm{H} & -19.16848300 & -0.60982400 & 2.31072400 \\ \mathrm{C} & -18.74192600 & 2.08255500 & 1.64772200 \\ \mathrm{H} & -18.18584500 & 3.02856200 & 1.72765000 \\ \mathrm{H} & -19.39981400 & 1.99500500 & 2.53184100 \\ \mathrm{H} & -19.41087600 & 2.14991900 & 0.77023400 \\ \mathrm{C} & 15.07969100 & -1.56496600 & -0.40913900 \\ \mathrm{H} & 14.75308400 & 0.61044600 & -0.14744200 \\ \mathrm{C} & 16.14646300 & -1.75818700 & 0.71318900 \\ \mathrm{H} & 15.63738300 & -1.52389900 & -1.36548000 \\ \mathrm{H} & 14.43649900 & -2.45805900 & -0.47359800 \\ \mathrm{C} & 16.81516400 & -3.13182000 & 0.55002900 \\ \mathrm{H} & 16.08233100 & -3.95337300 & 0.54362900 \\ \mathrm{H} & 17.52641600 & -3.30785200 & 1.37208800 \\ \mathrm{H} & 17.36835400 & -3.17805700 & -0.40116700 \\ \mathrm{C} & 17.21037200 & -0.65659700 & 0.66183100 \\ \mathrm{O} & 15.56468800 & -1.60001200 & 2.01793400 \\ \mathrm{H} & 17.96243300 & -0.83191900 & 1.44586800 \\ \mathrm{H} & 16.76233600 & 0.33008100 & 0.84954400 \\ \mathrm{H} & 17.71802900 & -0.63829500 & -0.31501700 \\ \mathrm{C} & 14.58149600 & -2.53241400 & 2.42186700 \\ \mathrm{H} & 14.24741900 & -2.21250300 & 3.41980000 \\ \mathrm{H} & 14.97514900 & -3.56292300 & 2.50349200 \\ \mathrm{H} & 13.70064100 & -2.54459000 & 1.75301500\end{array}$

3. $\mathrm{S}_{1}$ Geometry $(\mathrm{CASSCF}(\mathrm{NRoot}=2,4,4) / \mathrm{cc}-\mathrm{pVDZ})$, Bond-Length Alternation $=0.0140$
C $10.61845200 \quad 0.54195800 \quad-0.33992900$
C $11.94186900 \quad 0.86495000-0.32654600$
C $12.91672200-0.22393800-0.20008500$
C $14.24372800-0.10489300-0.18789000$
$\mathrm{H} 12.48889900-1.21800300-0.11081400$
C $9.506621001 .40898900-0.45408000$
$\mathrm{H} 10.37917300-0.51354500-0.25461700$
C $8.16174500 \quad 0.91946700-0.46513000$
H $9.66801100 \quad 2.47190700-0.53919300$
C $7.02948100 \quad 1.66625000-0.57176600$
$\mathrm{H} 8.04467900-0.15560800-0.38073300$
C $5.75794000 \quad 0.97558900-0.56824200$
C $4.48166200 \quad 1.52195600-0.65840500$
$\mathrm{H} \quad 5.81848100-0.10360100-0.48587900$
C $3.33588300 \quad 0.74992300-0.65294000$
$\mathrm{H} \quad 4.37617600 \quad 2.59437000 \quad-0.73694900$
C $1.99307200 \quad 1.22334200-0.74257400$
H $3.46205100-0.32437800-0.57461000$
C $0.95020700 \quad 0.26743100-0.73067900$ 


$\begin{array}{llll}\mathrm{C} & -0.39398400 & 0.48276800 & -0.80429100 \\ \mathrm{H} & 1.26849400 & -0.76778600 & -0.65402700 \\ \mathrm{C} & -1.36464100 & -0.58616800 & -0.78700100 \\ \mathrm{H} & -0.78410800 & 1.48904500 & -0.88081900 \\ \mathrm{C} & -2.70047500 & -0.37814400 & -0.85535800 \\ \mathrm{H} & -0.97127700 & -1.59195100 & -0.71495300 \\ \mathrm{C} & -3.74955600 & -1.35488500 & -0.84787200 \\ \mathrm{H} & -3.03178300 & 0.65348000 & -0.92310300 \\ \mathrm{C} & -5.10147200 & -0.88721600 & -0.91408100 \\ \mathrm{C} & -6.21559300 & -1.65088000 & -0.91430000 \\ \mathrm{H} & -5.23036600 & 0.18937900 & -0.96626400 \\ \mathrm{C} & -7.55798800 & -1.08370200 & -0.97618500 \\ \mathrm{H} & -6.11814400 & -2.72529100 & -0.85850900 \\ \mathrm{C} & -8.72551400 & -1.73682700 & -0.98987900 \\ \mathrm{H} & -7.59274200 & 0.00063900 & -1.01006200 \\ \mathrm{C} & 12.46070200 & 2.27417300 & -0.43447100 \\ \mathrm{H} & 13.06724600 & 2.52752700 & 0.43860100 \\ \mathrm{H} & 11.66331900 & 3.00785800 & -0.50987700 \\ \mathrm{H} & 13.09878900 & 2.38317800 & -1.31534600 \\ \mathrm{C} & 7.10297400 & 3.17345000 & -0.69171300 \\ \mathrm{H} & 6.12291900 & 3.63209400 & -0.78594500 \\ \mathrm{H} & 7.68424500 & 3.46610400 & -1.56870600 \\ \mathrm{H} & 7.58519900 & 3.61138200 & 0.18500600 \\ \mathrm{C} & 1.73445700 & 2.70358900 & -0.84737700 \\ \mathrm{H} & 2.21868700 & 3.12101600 & -1.73432200 \\ \mathrm{H} & 2.13657700 & 3.23121100 & 0.02172200 \\ \mathrm{H} & 0.67569400 & 2.93712100 & -0.91206000 \\ \mathrm{C} & -3.47543700 & -2.83171900 & -0.77166400 \\ \mathrm{H} & -2.41328500 & -3.05699800 & -0.73979200 \\ \mathrm{H} & -3.89655900 & -3.34982800 & -1.63769800 \\ \mathrm{H} & -3.93324800 & -3.26731900 & 0.12091400 \\ \mathrm{C} & -8.86084800 & -3.23985900 & -0.96171800 \\ \mathrm{H} & -7.91911900 & -3.75619600 & -1.13013600 \\ \mathrm{H} & -9.56271000 & -3.56815000 & -1.73355700 \\ \mathrm{H} & -9.25940600 & -3.58159900 & -0.00249400 \\ \mathrm{C} & -10.02637800 & -0.96392100 & -1.03470800 \\ \mathrm{C} & -10.86753900 & -1.07510600 & 0.25110900 \\ \mathrm{H} & -10.63099400 & -1.31909200 & -1.87649100 \\ \mathrm{H} & -9.81482000 & 0.08982400 & -1.22754300 \\ \mathrm{C} & -12.09472300 & -0.20216100 & 0.20337900 \\ \mathrm{H} & -10.24639000 & -0.75789700 & 1.09538000 \\ \mathrm{H} & -11.13128500 & -2.11432100 & 0.43961000 \\ \mathrm{C} & -13.37647400 & -0.55773300 & 0.20268000 \\ \mathrm{H} & -11.87798000 & 0.86263400 & 0.15931100 \\ \mathrm{C} & -13.87061800 & -1.98568100 & 0.24020600 \\ \mathrm{H} & -13.08035000 & -2.71362000 & 0.07382200 \\ \mathrm{H} & -14.63236100 & -2.13937100 & -0.52937000\end{array}$




$\begin{array}{llll}\mathrm{H} & -14.33773000 & -2.21752600 & 1.20111400 \\ \mathrm{C} & -14.46077500 & 0.50148500 & 0.16315000 \\ \mathrm{C} & -15.28950300 & 0.60130700 & 1.45692700 \\ \mathrm{H} & -15.14107200 & 0.29443800 & -0.67020300 \\ \mathrm{H} & -14.00767300 & 1.47386100 & -0.04092400 \\ \mathrm{C} & -16.27749900 & 1.73762600 & 1.40966000 \\ \mathrm{H} & -14.60120800 & 0.76941500 & 2.29215700 \\ \mathrm{H} & -15.78893500 & -0.34516000 & 1.65680100 \\ \mathrm{C} & -17.60588600 & 1.69507600 & 1.43998500 \\ \mathrm{H} & -15.81823400 & 2.72042300 & 1.33298700 \\ \mathrm{C} & -18.43667400 & 0.43902100 & 1.53810400 \\ \mathrm{H} & -17.84504600 & -0.47280900 & 1.55046000 \\ \mathrm{H} & -19.12989600 & 0.37888800 & 0.69365600 \\ \mathrm{H} & -19.04708200 & 0.45787500 & 2.44617300 \\ \mathrm{C} & -18.42063800 & 2.96498200 & 1.37961900 \\ \mathrm{H} & -17.78884500 & 3.85062700 & 1.31404200 \\ \mathrm{H} & -19.05399400 & 3.06213400 & 2.26704600 \\ \mathrm{H} & -19.08928700 & 2.95682700 & 0.51312000 \\ \mathrm{C} & 15.19023400 & -1.26972800 & -0.08490300 \\ \mathrm{H} & 14.69111700 & 0.87648500 & -0.27846300 \\ \mathrm{C} & 16.29870800 & -1.12221800 & 0.98328300 \\ \mathrm{H} & 15.68977100 & -1.41718400 & -1.04890100 \\ \mathrm{H} & 14.61744800 & -2.18163200 & 0.09509200 \\ \mathrm{C} & 17.04730900 & -2.45109300 & 1.12883500 \\ \mathrm{H} & 16.37593200 & -3.28040000 & 1.35698600 \\ \mathrm{H} & 17.78996800 & -2.38071000 & 1.92583400 \\ \mathrm{H} & 17.56480900 & -2.69521800 & 0.19894200 \\ \mathrm{C} & 17.29020900 & -0.02195500 & 0.60586400 \\ \mathrm{O} & 15.76862100 & -0.68566500 & 2.22089700 \\ \mathrm{H} & 18.07799900 & 0.03500200 & 1.35823200 \\ \mathrm{H} & 16.79870600 & 0.94980900 & 0.57249700 \\ \mathrm{H} & 17.74890500 & -0.21876500 & -0.36521600 \\ \mathrm{C} & 14.89999000 & -1.51820300 & 2.92761400 \\ \mathrm{H} & 14.53470800 & -0.93980700 & 3.77477900 \\ \mathrm{H} & 15.40225700 & -2.40972100 & 3.31352200 \\ \mathrm{H} & 14.03819000 & -1.82956100 & 2.33281000\end{array}$

\section{4. $\mathrm{S}_{1}$ Geometry $(\mathrm{CASSCF}(\mathrm{NRoot}=2,6,6) / \mathrm{cc}-\mathrm{pVDZ})$, Bond-Length Alternation $=0.0140$}
C $10.61845200 \quad 0.54195800-0.33992900$
C $11.94186900 \quad 0.86495000-0.32654600$
C $12.91672200-0.22393800-0.20008500$
C $14.24372800-0.10489300-0.18789000$
$\mathrm{H} 12.48889900-1.21800300-0.11081400$
C $9.506621001 .40898900-0.45408000$
$\mathrm{H} 10.37917300-0.51354500-0.25461700$
C $8.16174500 \quad 0.91946700-0.46513000$ 

H $9.668011002 .47190700-0.53919300$
C $7.029481001 .66625000-0.57176600$
H $8.04467900-0.15560800-0.38073300$
$\begin{array}{llll}\text { C } 5.75794000 & 0.97558900 & -0.56824200\end{array}$
C $4.481662001 .52195600-0.65840500$
H $5.81848100-0.10360100-0.48587900$
C $3.33588300 \quad 0.74992300-0.65294000$
H $4.37617600 \quad 2.59437000-0.73694900$
C $1.993072001 .22334200-0.74257400$
H $3.46205100-0.32437800-0.57461000$
$\begin{array}{lllll}\text { C } & 0.95020700 & 0.26743100 & -0.73067900\end{array}$
C $-0.39398400 \quad 0.48276800 \quad-0.80429100$
$\mathrm{H} \quad 1.26849400-0.76778600 \quad-0.65402700$
C $-1.36464100-0.58616800-0.78700100$
$\mathrm{H}-0.78410800 \quad 1.48904500 \quad-0.88081900$
C $-2.70047500-0.37814400-0.85535800$
$\mathrm{H}-0.97127700-1.59195100-0.71495300$
C $-3.74955600-1.35488500-0.84787200$
$\mathrm{H}-3.03178300 \quad 0.65348000 \quad-0.92310300$
C $-5.10147200-0.88721600-0.91408100$
C $-6.21559300-1.65088000-0.91430000$
$\mathrm{H}-5.23036600 \quad 0.18937900-0.96626400$
C $-7.55798800-1.08370200-0.97618500$
$\mathrm{H}-6.11814400-2.72529100-0.85850900$
C $-8.72551400-1.73682700-0.98987900$
$\mathrm{H}-7.59274200 \quad 0.00063900-1.01006200$
$\begin{array}{llll}\text { C } 12.46070200 & 2.27417300 & -0.43447100\end{array}$
H $13.06724600 \quad 2.52752700 \quad 0.43860100$
H $11.66331900 \quad 3.00785800 \quad-0.50987700$
$\mathrm{H} 13.09878900 \quad 2.38317800-1.31534600$
C $7.10297400 \quad 3.17345000-0.69171300$
H $6.12291900 \quad 3.63209400-0.78594500$
H $7.68424500 \quad 3.46610400-1.56870600$
$\mathrm{H} 7.58519900 \quad 3.61138200 \quad 0.18500600$
C $1.73445700 \quad 2.70358900-0.84737700$
H $2.21868700 \quad 3.12101600-1.73432200$
H $2.13657700 \quad 3.23121100 \quad 0.02172200$
$\mathrm{H} \quad 0.67569400 \quad 2.93712100-0.91206000$
C $-3.47543700-2.83171900-0.77166400$
$\mathrm{H}-2.41328500-3.05699800-0.73979200$
$\mathrm{H}-3.89655900-3.34982800-1.63769800$
$\mathrm{H}-3.93324800 \quad-3.26731900 \quad 0.12091400$
C $-8.86084800-3.23985900-0.96171800$
$\mathrm{H}-7.91911900-3.75619600-1.13013600$
$\mathrm{H}-9.56271000-3.56815000-1.73355700$
$\mathrm{H}-9.25940600-3.58159900-0.00249400$
C $-10.02637800-0.96392100-1.03470800$ 


\begin{tabular}{|c|c|c|}
\hline & -10.86753900 & $-1.07510600 \quad 0.25110900$ \\
\hline & -10.63099400 & $-1.31909200-1.87649100$ \\
\hline & -9.81482000 & $0.08982400-1.22754300$ \\
\hline & -12.09472300 & $-0.20216100 \quad 0.20337900$ \\
\hline & -10.24639000 & $-0.75789700 \quad 1.09538000$ \\
\hline & -11.13128500 & $-2.11432100 \quad 0.43961000$ \\
\hline & -13.37647400 & $-0.55773300 \quad 0.20268000$ \\
\hline & -11.87798000 & $0.86263400 \quad 0.15931100$ \\
\hline & -13.87061800 & $-1.98568100 \quad 0.24020600$ \\
\hline & -13.08035000 & $-2.71362000 \quad 0.07382200$ \\
\hline & -14.63236100 & $-2.13937100-0.52937000$ \\
\hline & -14.3377 & -2.217526001 .20 \\
\hline & -14.46077500 & $0.50148500 \quad 0.1631$ \\
\hline & -15.28950300 & $0.60130700 \quad 1.45692700$ \\
\hline & -15.14107200 & $0.29443800-0.67$ \\
\hline & -14.00 & $1.47386100-0.040$ \\
\hline & -16.27749900 & $1.73762600 \quad 1.40966000$ \\
\hline & -14.60 & $0.76941500 \quad 2.29215700$ \\
\hline & -15.78893500 & -0.345160001 .65 \\
\hline & -17.60588600 & 1.695076001 .4399 \\
\hline & -15.81 & 2.720423001 .332 \\
\hline & -18.43667400 & $0.43902100 \quad 1.53810400$ \\
\hline & -17.84 & $-0.47280900 \quad 1.55046000$ \\
\hline & -19.129896 & $0.37888800 \quad 0.69365600$ \\
\hline & -19.04 & $0.45787500 \quad 2.44617300$ \\
\hline & -18.42 & 2.964982001 .37961900 \\
\hline & -17.78884500 & 3.850627001 .31404200 \\
\hline & -19.053 & $3.06213400 \quad 2.267$ \\
\hline & -19.08 & $2.95682700 \quad 0.51312000$ \\
\hline & 15.190 & $-1.26972800-0.08$ \\
\hline & 14.691 & $0.87648500-0.27846$ \\
\hline & 16.29870800 & $-1.12221800 \quad 0.98328300$ \\
\hline & 15.68977100 & $-1.41718400-1.04890100$ \\
\hline & 14.617 & $-2.18163200 \quad 0.09509200$ \\
\hline & 17.0473 & $-2.45109300 \quad 1.12883500$ \\
\hline & 16.37593 & -3.280400001 .35698600 \\
\hline & 17.78996800 & $-2.38071000 \quad 1.92583400$ \\
\hline & 17.56480900 & $-2.69521800 \quad 0.19894200$ \\
\hline & 17.29020900 & $-0.02195500 \quad 0.60586400$ \\
\hline & 15.76862100 & $-0.68566500 \quad 2.22089700$ \\
\hline & 18.07799900 & $0.03500200 \quad 1.35823200$ \\
\hline & 16.79870600 & $0.94980900 \quad 0.57249700$ \\
\hline & 17.74890500 & $-0.21876500-0.36521600$ \\
\hline & 14.89999000 & $-1.51820300 \quad 2.92761400$ \\
\hline & 14.53470800 & $\begin{array}{l}-0.93980700 \quad 3.77477900\end{array}$ \\
\hline & 15.40225700 & $-2.40972100 \quad 3.31352200$ \\
\hline & 14.0381 & -1.829561002 .33 \\
\hline
\end{tabular}




\section{5. $\mathrm{S}_{1}$ Geometry $(\mathrm{CASSCF}(\mathrm{NRoot}=2,8,8) / \mathrm{cc}-\mathrm{pVDZ})$, Bond-Length Alternation $=0.0140$}
C $10.61845200 \quad 0.54195800-0.33992900$
C $11.94186900 \quad 0.86495000-0.32654600$
C $12.91672200-0.22393800-0.20008500$
C $14.24372800-0.10489300-0.18789000$
$\mathrm{H} 12.48889900-1.21800300-0.11081400$
C $9.506621001 .40898900-0.45408000$
H $10.37917300-0.51354500-0.25461700$
C $8.16174500 \quad 0.91946700-0.46513000$
H $9.66801100 \quad 2.47190700-0.53919300$
C $7.029481001 .66625000-0.57176600$
H $8.04467900-0.15560800-0.38073300$
C $5.75794000 \quad 0.97558900-0.56824200$
C $4.481662001 .52195600-0.65840500$
H $5.81848100-0.10360100-0.48587900$
C $3.33588300 \quad 0.74992300-0.65294000$
$\mathrm{H} 4.37617600 \quad 2.59437000-0.73694900$
C $1.993072001 .22334200-0.74257400$
H $3.46205100-0.32437800-0.57461000$
$\begin{array}{lllll}\text { C } & 0.95020700 & 0.26743100 & -0.73067900\end{array}$
C $-0.39398400 \quad 0.48276800 \quad-0.80429100$
$\mathrm{H} \quad 1.26849400 \quad-0.76778600 \quad-0.65402700$
C $-1.36464100-0.58616800-0.78700100$
$\mathrm{H}-0.78410800 \quad 1.48904500 \quad-0.88081900$
C $-2.70047500-0.37814400-0.85535800$
$\mathrm{H}-0.97127700-1.59195100-0.71495300$
C $-3.74955600-1.35488500-0.84787200$
$\mathrm{H}-3.03178300 \quad 0.65348000-0.92310300$
C $-5.10147200-0.88721600-0.91408100$
C $-6.21559300-1.65088000-0.91430000$
$\mathrm{H}-5.23036600 \quad 0.18937900-0.96626400$
C $-7.55798800-1.08370200-0.97618500$
$\mathrm{H}-6.11814400-2.72529100-0.85850900$
C $-8.72551400-1.73682700-0.98987900$
$\mathrm{H}-7.59274200 \quad 0.00063900-1.01006200$
C $12.46070200 \quad 2.27417300 \quad-0.43447100$
$\mathrm{H} 13.06724600 \quad 2.52752700 \quad 0.43860100$
$\mathrm{H} 11.66331900 \quad 3.00785800 \quad-0.50987700$
H $13.09878900 \quad 2.38317800-1.31534600$
C $7.10297400 \quad 3.17345000-0.69171300$
H $6.12291900 \quad 3.63209400-0.78594500$
H $7.68424500 \quad 3.46610400-1.56870600$
H $7.58519900 \quad 3.61138200 \quad 0.18500600$
$\begin{array}{llll}\text { C } 1.73445700 & 2.70358900 & -0.84737700\end{array}$
H $2.21868700 \quad 3.12101600-1.73432200$
H $2.13657700 \quad 3.23121100 \quad 0.02172200$ 
$\mathrm{H} \quad 0.67569400 \quad 2.93712100 \quad-0.91206000$

C $-3.47543700-2.83171900-0.77166400$

$\mathrm{H}-2.41328500-3.05699800-0.73979200$

$\mathrm{H}-3.89655900-3.34982800-1.63769800$

$\mathrm{H}-3.93324800 \quad-3.26731900 \quad 0.12091400$

C $-8.86084800-3.23985900-0.96171800$

$\mathrm{H}-7.91911900-3.75619600-1.13013600$

$\mathrm{H}-9.56271000-3.56815000-1.73355700$

$\mathrm{H}-9.25940600-3.58159900-0.00249400$

C $-10.02637800-0.96392100-1.03470800$

C $-10.86753900-1.07510600 \quad 0.25110900$

$\mathrm{H}-10.63099400-1.31909200-1.87649100$

$\mathrm{H}-9.81482000 \quad 0.08982400 \quad-1.22754300$

C $-12.09472300-0.20216100 \quad 0.20337900$

$\mathrm{H}-10.24639000-0.75789700 \quad 1.09538000$

$\mathrm{H}-11.13128500-2.11432100 \quad 0.43961000$

$\begin{array}{llll}\text { C }-13.37647400 & -0.55773300 & 0.20268000\end{array}$

$\mathrm{H}-11.87798000 \quad 0.86263400 \quad 0.15931100$

C $-13.87061800-1.98568100 \quad 0.24020600$

$\mathrm{H}-13.08035000-2.71362000 \quad 0.07382200$

$\mathrm{H}-14.63236100-2.13937100-0.52937000$

$\mathrm{H}-14.33773000-2.21752600 \quad 1.20111400$

C $-14.46077500 \quad 0.50148500 \quad 0.16315000$

C $-15.28950300 \quad 0.60130700 \quad 1.45692700$

$\mathrm{H}-15.14107200 \quad 0.29443800-0.67020300$

$\mathrm{H}-14.00767300 \quad 1.47386100-0.04092400$

C $-16.27749900 \quad 1.73762600 \quad 1.40966000$

$\mathrm{H}-14.60120800 \quad 0.76941500 \quad 2.29215700$

$\mathrm{H}-15.78893500-0.34516000 \quad 1.65680100$

C $-17.60588600 \quad 1.69507600 \quad 1.43998500$

$\mathrm{H}-15.81823400 \quad 2.72042300 \quad 1.33298700$

C $-18.43667400 \quad 0.43902100 \quad 1.53810400$

$\mathrm{H}-17.84504600-0.47280900 \quad 1.55046000$

$\mathrm{H}-19.12989600 \quad 0.37888800 \quad 0.69365600$

$\mathrm{H}-19.04708200 \quad 0.45787500 \quad 2.44617300$

C $-18.42063800 \quad 2.96498200 \quad 1.37961900$

$\mathrm{H}-17.78884500 \quad 3.85062700 \quad 1.31404200$

$\mathrm{H}-19.05399400 \quad 3.06213400 \quad 2.26704600$

$\mathrm{H}-19.08928700 \quad 2.95682700 \quad 0.51312000$

C $15.19023400-1.26972800-0.08490300$

H $14.69111700 \quad 0.87648500 \quad-0.27846300$

C $16.29870800-1.12221800 \quad 0.98328300$

$\mathrm{H} 15.68977100-1.41718400-1.04890100$

$\mathrm{H} \quad 14.61744800-2.18163200 \quad 0.09509200$

C $17.04730900-2.45109300 \quad 1.12883500$

$\mathrm{H} 16.37593200-3.28040000 \quad 1.35698600$

$\mathrm{H} \quad 17.78996800 \quad-2.38071000 \quad 1.92583400$ 

H $17.56480900 \quad-2.69521800 \quad 0.19894200$
C $17.29020900-0.02195500 \quad 0.60586400$
$\begin{array}{lllll}0 & 15.76862100 & -0.68566500 & 2.22089700\end{array}$
$\mathrm{H} 18.07799900 \quad 0.03500200 \quad 1.35823200$
$\mathrm{H} \quad 16.79870600 \quad 0.94980900 \quad 0.57249700$
$\mathrm{H} \quad 17.74890500-0.21876500-0.36521600$
C $14.89999000-1.51820300 \quad 2.92761400$
$\mathrm{H} \quad 14.53470800 \quad-0.93980700 \quad 3.77477900$
$\mathrm{H} 15.40225700-2.40972100 \quad 3.31352200$
$\mathrm{H} \quad 14.03819000-1.82956100 \quad 2.33281000$

\section{Neurosporene}

\section{$\mathrm{S}_{0}$ Geometry (B3LYP/cc-pVDZ):}

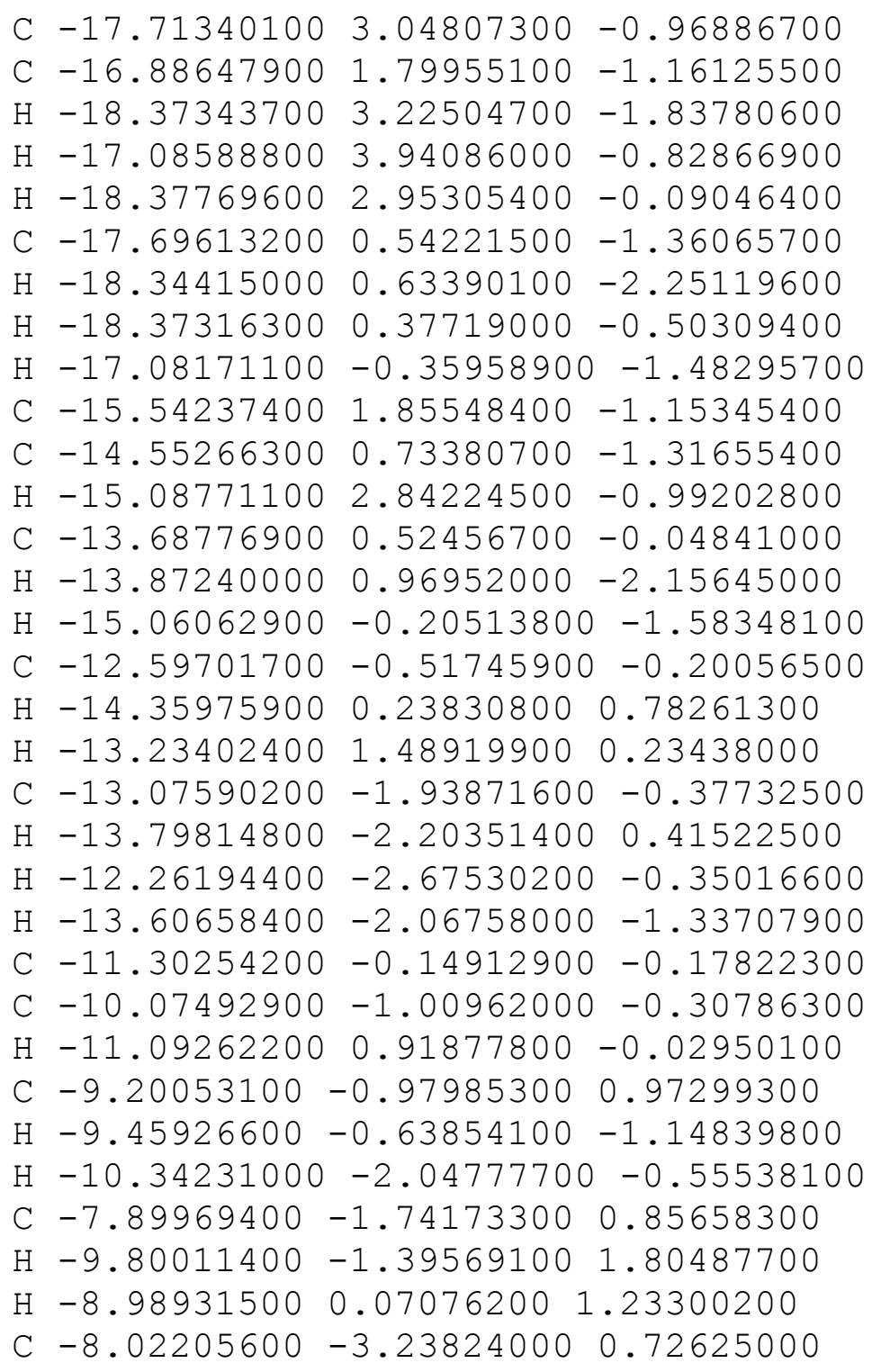




\begin{tabular}{|c|c|c|}
\hline $\mathrm{H}$ & -8.67874200 & $-3.64208300 \quad 1.51739400$ \\
\hline $\mathrm{H}$ & -7.05817900 & -3.75971000 \\
\hline $\mathrm{H}$ & -8.48673900 & -3.52002800 \\
\hline & -6.71654200 & $-1.07460200 \quad 0.86769200$ \\
\hline & -5.38454500 & $-1.62745700 \quad 0.75631200$ \\
\hline & -6.76050100 & $0.01627600 \quad 0.97518000$ \\
\hline & -4.25601300 & $-0.86429400 \quad 0.78045500$ \\
\hline & -5.28810200 & $-2.71027800 \quad 0.64567100$ \\
\hline & -2.89050100 & $-1.33698300 \quad 0.67771400$ \\
\hline & -4.37575100 & $0.22061100 \quad 0.88800600$ \\
\hline & -2.65303300 & $-2.81948900 \quad 0.52977900$ \\
\hline & -3.07853400 & $-3.37209800 \quad 1.38472600$ \\
\hline & -1.58865400 & $-3.07542600 \quad 0.46380500$ \\
\hline & -3.14788400 & $-3.20734800-0.37693300$ \\
\hline & -1.87386200 & $-0.41271400 \quad 0.72073600$ \\
\hline & -0.46326400 & $-0.64540100 \quad 0.64162700$ \\
\hline & -2.17154800 & $0.63721500 \quad 0.83004200$ \\
\hline & 0.47544000 & $0.35157100 \quad 0.69435000$ \\
\hline & -0.10612300 & $-1.67452400 \quad 0.53361400$ \\
\hline & 1.88490600 & $0.11790000 \quad 0.61754100$ \\
\hline & 0.11855800 & $1.38080300 \quad 0.80200000$ \\
\hline & 2.90411500 & $1.04222600 \quad 0.66079100$ \\
\hline $\mathrm{H}$ & 2.18238500 & $-0.93243800 \quad 0.51174700$ \\
\hline & 2.66605700 & $2.52587300 \quad 0.80231100$ \\
\hline & 1.60133100 & $2.78134600 \quad 0.86413600$ \\
\hline $\mathrm{H}$ & 3.09294500 & $3.07530800-0.05389100$ \\
\hline $\mathrm{H}$ & 3.15772800 & $2.91780300 \quad 1.70887800$ \\
\hline $\mathrm{C}$ & 4.26480600 & $0.56773400 \quad 0.56680200$ \\
\hline $\mathrm{C}$ & 5.39917800 & $1.33184100 \quad 0.59282800$ \\
\hline & 4.38504900 & $-0.51757300 \quad 0.46541800$ \\
\hline $\mathrm{C}$ & 6.71912100 & $0.77806800 \quad 0.49505500$ \\
\hline $\mathrm{H}$ & 5.30120700 & $2.41528000 \quad 0.69320400$ \\
\hline $\mathrm{C}$ & 7.92130100 & $1.44220600 \quad 0.51096900$ \\
\hline $\mathrm{H}$ & 6.76430700 & $-0.31329100 \quad 0.39613900$ \\
\hline & 8.03586200 & $2.94112800 \quad 0.64004600$ \\
\hline $\mathrm{H}$ & 7.06075300 & $3.43660400 \quad 0.72158800$ \\
\hline $\mathrm{H}$ & 8.55864500 & $3.37143300-0.23119400$ \\
\hline $\mathrm{H}$ & 8.62635600 & $3.21441100 \quad 1.53116400$ \\
\hline $\mathrm{C}$ & 9.13978800 & $0.66523700 \quad 0.39922200$ \\
\hline $\mathrm{C}$ & 10.41405900 & $1.14672400 \quad 0.39624600$ \\
\hline $\mathrm{H}$ & 9.00371600 & $-0.41928400 \quad 0.30825400$ \\
\hline & 11.58068400 & $0.29870300 \quad 0.28136600$ \\
\hline & 10.57219600 & $2.22457700 \quad 0.48188700$ \\
\hline $\mathrm{C}$ & 12.88614700 & $0.67312200 \quad 0.27052700$ \\
\hline & 11.36941800 & $-0.77432600 \quad 0.19457500$ \\
\hline & 13.35419000 & $2.10095200 \quad 0.38891800$ \\
\hline & 13.81842 & $2.45009300-0.55083500$ \\
\hline
\end{tabular}



H $14.13104100 \quad 2.18911700 \quad 1.16931600$
$\mathrm{H} \quad 12.54726100 \quad 2.80259600 \quad 0.63753100$
C $13.97251500-0.36878700 \quad 0.12665200$
C $14.75890900-0.29108700-1.20827000$
H $13.53118200-1.37509900 \quad 0.21954900$
H $14.69780100-0.26515000 \quad 0.95595200$
C $15.75324600-1.41147200-1.34933200$
H $15.25185700 \quad 0.68882900-1.29487900$
$\mathrm{H} 14.02818700-0.34701300-2.03654900$
C $17.09506400-1.34115500-1.41631000$
H $15.30602200-2.41398100-1.38524100$
C $17.89474300-0.06247800-1.37674300$
$\mathrm{H} \quad 18.49269300 \quad 0.05095200 \quad-2.29919900$
$\mathrm{H} 18.61808300-0.08365300-0.54171500$
$\mathrm{H} \quad 17.27636200 \quad 0.83782900 \quad-1.26373300$
C $17.92896500-2.59279700-1.54861700$
H $18.64049600-2.68651200-0.70791100$
$\mathrm{H} 18.54004200-2.56713200-2.46942100$
$\mathrm{H} \quad 17.30851100-3.50097300-1.57509300$

\section{$\underline{\beta \text {-Carotene }}$}

\section{$\mathrm{S}_{0}$ Geometry (B3LYP/cc-pVDZ):}

C $12.75972000-0.46418000-0.69401000$

C $6.75223800 \quad-0.52929200 \quad 0.28426300$

C $12.25526900-0.56985300-2.15203200$

C $13.11771800-1.88513000-0.19943900$

C $5.45889800-1.14058800 \quad 0.41178100$

C $4.28947600-0.46072700 \quad 0.21231200$

C $2.95235300-0.99618400 \quad 0.32054200$

C $2.78536400-2.44968900 \quad 0.69047300$

C $1.88981400-0.15406800 \quad 0.08091100$

C $0.49333700-0.45850000 \quad 0.12853200$

C $14.05658800 \quad 0.37652600 \quad-0.64331900$

C $13.79429100 \quad 1.87585000-0.73739600$

C $12.94858600 \quad 2.31264800 \quad 0.45514200$

C $11.772120001 .40169900 \quad 0.73933100$

C $10.79683900 \quad 1.99997700 \quad 1.72530700$

C $11.65066800 \quad 0.16360200 \quad 0.18755600$

C $10.45675900-0.68156000 \quad 0.38570300$

C $9.16541800-0.27754100 \quad 0.27640100$

C $7.98383700-1.10748300 \quad 0.45870100$

C $8.17326800 \quad-2.55685200 \quad 0.82937600$

C $-12.75967500 \quad 0.46455500 \quad 0.69391500$

C $-6.75215000 \quad 0.52913800 \quad-0.28441600$

C $-12.25535200 \quad 0.57038000 \quad 2.15197800$ 


$\begin{array}{llll}\text { C } & -13.11730600 & 1.88549400 & 0.19906800 \\ \text { C } & -5.45881700 & 1.14042400 & -0.41208600 \\ \text { C } & -4.28939000 & 0.46061400 & -0.21249600 \\ \text { C } & -2.95228100 & 0.99611700 & -0.32079200 \\ \text { C } & -2.78547500 & 2.44959800 & -0.69085800 \\ \text { C } & -1.88969800 & 0.15408600 & -0.08105600 \\ \text { C } & -0.4932600 & 0.45852500 & -0.12872600 \\ \text { C } & -14.05672700 & -0.37586300 & 0.64323400 \\ \text { C } & -13.79483900 & -1.87522500 & 0.73780100 \\ \text { C } & -12.94886100 & -2.31263200 & -0.45431800 \\ \text { C } & -11.77219300 & -1.40198400 & -0.73863400 \\ \text { C } & -10.79683200 & -2.00080200 & -1.72420500 \\ \text { C } & -11.65064500 & -0.16366500 & -0.18737100 \\ \text { C } & -10.45667300 & 0.68132500 & -0.38582000 \\ \text { C } & -9.16532900 & 0.27733900 & -0.27641100 \\ \text { C } & -7.98376800 & 1.10726000 & -0.45895800 \\ \text { C } & -8.17321800 & 2.55652000 & -0.83004700 \\ \text { H } & 6.74379000 & 0.53364300 & 0.01408400 \\ \text { H } & 12.06180400 & 0.42259100 & -2.58848200 \\ \text { H } & 11.31427400 & -1.13952000 & -2.20434000 \\ \text { H } & 13.00008600 & -1.08260000 & -2.78437100 \\ \text { H } & 13.35479800 & -1.88715700 & 0.87694100 \\ \text { H } & 14.00516300 & -2.25271800 & -0.74089500 \\ \text { H } & 12.31001800 & -2.61137200 & -0.37566800 \\ \text { H } & 3.28564200 & -3.10202300 & -0.04527900 \\ \text { H } & 1.73381000 & -2.75603000 & 0.74624400 \\ \text { H } & 3.24800300 & -2.66108500 & 1.66946500 \\ \text { H } & 14.57935900 & 0.17016100 & 0.30861700 \\ \text { H } & 14.73053300 & 0.04044500 & -1.44963800 \\ \text { H } & 14.74271500 & 2.43725800 & -0.76169100 \\ \text { H } & 13.26588700 & 2.11127500 & -1.67736300 \\ \text { H } & 12.56932300 & 3.34075300 & 0.30765600 \\ \text { H } & 13.57847000 & 2.36922300 & 1.36610800 \\ \text { H } & 11.35357900 & 2.49742100 & 2.53969400 \\ \text { H } & 10.12087400 & 1.25821000 & 2.16835800 \\ \text { H } & 10.17663600 & 2.78605000 & 1.25649100 \\ \text { H } & 10.64363900 & -1.74073200 & 0.58302100 \\ \text { H } & 8.96696600 & 0.76528300 & 0.00832100 \\ \text { H } & 8.75913400 & -3.08594200 & 0.05819700 \\ \text { H } & 7.22369200 & -3.09221800 & 0.95092500 \\ \text { H } & 8.73645800 & -2.65098600 & 1.77331700 \\ \text { H } & -6.74367900 & -0.53373300 & -0.01398200 \\ \text { H } & -11.31416600 & 1.13973400 & 2.20425200 \\ \text { H } & -12.06228200 & -0.42203000 & 2.58867700 \\ \text { H } & -13.00006000 & 1.08353500 & 2.78411600 \\ \text { H } & -12.30946900 & 2.61158700 & 0.37527200 \\ \text { H } & -14.00473500 & 2.25336200 & 0.74036100\end{array}$




$\begin{array}{llll}\mathrm{H} & -13.35426400 & 1.88740800 & -0.87734000 \\ \mathrm{H} & -1.73396300 & 2.75588300 & -0.74749900 \\ \mathrm{H} & -3.28508000 & 3.10191500 & 0.04538400 \\ \mathrm{H} & -3.24899400 & 2.66108100 & -1.66941900 \\ \mathrm{H} & -14.57929700 & -0.16962300 & -0.30883900 \\ \mathrm{H} & -14.73071300 & -0.03939800 & 1.44936100 \\ \mathrm{H} & -14.74342900 & -2.43636200 & 0.76192400 \\ \mathrm{H} & -13.26684900 & -2.11053800 & 1.67802700 \\ \mathrm{H} & -12.56980500 & -3.34073800 & -0.30630400 \\ \mathrm{H} & -13.57849500 & -2.36949300 & -1.36544100 \\ \mathrm{H} & -10.12085300 & -1.25926300 & -2.16762500 \\ \mathrm{H} & -11.35348700 & -2.49872200 & -2.53836000 \\ \mathrm{H} & -10.17663000 & -2.78658000 & -1.25490200 \\ \mathrm{H} & -10.64350600 & 1.74044300 & -0.58349200 \\ \mathrm{H} & -8.96684500 & -0.76539400 & -0.00799700 \\ \mathrm{H} & -7.22364700 & 3.09187800 & -0.95165700 \\ \mathrm{H} & -8.75918100 & 3.08581600 & -0.05908400 \\ \mathrm{H} & -8.73631800 & 2.65036900 & -1.77407500 \\ \mathrm{H} & -5.41337500 & 2.19808000 & -0.68188100 \\ \mathrm{H} & -4.35733600 & -0.59993400 & 0.05811500 \\ \mathrm{H} & -2.13682100 & -0.88208900 & 0.17991200 \\ \mathrm{H} & -0.18580300 & 1.47764200 & -0.38389100 \\ \mathrm{H} & 0.18590500 & -1.47762200 & 0.38366600 \\ \mathrm{H} & 2.13698700 & 0.88214100 & -0.17987400 \\ \mathrm{H} & 4.35744900 & 0.59986200 & -0.05813100 \\ \mathrm{H} & 5.41344900 & -2.19829500 & 0.68137200\end{array}$

\section{Lycopene}

\section{$\mathrm{S}_{0}$ Geometry (B3LYP/cc-pVDZ):}

$\begin{array}{llll}\mathrm{C} & 4.23510200 & 0.84761700 & 0.02024800 \\ \mathrm{C} & 5.34688100 & 1.63103700 & 0.17135900 \\ \mathrm{C} & 6.68192000 & 1.14261400 & -0.01915600 \\ \mathrm{C} & 7.86361300 & 1.83227400 & 0.10450400 \\ \mathrm{H} & 5.21690700 & 2.67923100 & 0.45052300 \\ \mathrm{H} & 6.75981400 & 0.08478900 & -0.29813300 \\ \mathrm{C} & 2.86243500 & 1.25876300 & 0.19284400 \\ \mathrm{H} & 4.38684900 & -0.20160700 & -0.26030800 \\ \mathrm{C} & 1.86949400 & 0.32428500 & -0.00350900 \\ \mathrm{C} & 2.58110200 & 2.69028100 & 0.57955500 \\ \mathrm{C} & 0.45570000 & 0.50089100 & 0.10978100 \\ \mathrm{H} & 2.19712600 & -0.68464500 & -0.28210500 \\ \mathrm{C} & -0.45569900 & -0.50118500 & -0.10805300 \\ \mathrm{H} & 0.06948600 & 1.48741800 & 0.38523900 \\ \mathrm{C} & -1.86949200 & -0.32455000 & 0.00521000 \\ \mathrm{H} & -0.06949400 & -1.48771400 & -0.38351300\end{array}$




\begin{tabular}{|c|c|c|}
\hline & -2.86245100 & $-1.25901900-0.191$ \\
\hline & -2.19710800 & $0.68441100 \quad 0.28371500$ \\
\hline & -4.23511400 & $-0.84780000-0.01864000$ \\
\hline & -2.58114200 & $-2.69059100-0.57761700$ \\
\hline & & $-1.63118000-0.16975700$ \\
\hline & -4.386 & $0.20146600 \quad 0.26177100$ \\
\hline & 9.10469000 & $1.12400400-0.13803100$ \\
\hline & 7.93249900 & $3.29177600 \quad 0.48103300$ \\
\hline & 10.36317100 & $1.64009600-0.06340200$ \\
\hline & 9.00191500 & $0.06598100-0.40793300$ \\
\hline & 11.55423000 & $0.85949000-0.32315400$ \\
\hline & 10.48607600 & $2.69209700 \quad 0.20455100$ \\
\hline & 12.84337900 & $1.28023100-0.27277700$ \\
\hline & 11.36866600 & $-0.18732400-0.57809500$ \\
\hline & 13.25640100 & $2.68598900 \quad 0.08232600$ \\
\hline & 14.01574200 & $0.37527100-0.59123400$ \\
\hline & -6.68194800 & $-1.14263300 \quad 0.02052700$ \\
\hline & -5.21698200 & $-2.67941900-0.44877100$ \\
\hline & -7.86367600 & $-1.83223500-0.10310900$ \\
\hline & -6.75979700 & $-0.08474200 \quad 0.29926300$ \\
\hline & -9.10472900 & $-1.12380500 \quad 0.13907900$ \\
\hline & -7.93262400 & $-3.29183000-0.47926500$ \\
\hline & -10.3632440 & $0-1.63980900 \quad 0.06442400$ \\
\hline & -9.00190300 & $-0.06571400 \quad 0.40869700$ \\
\hline & -11.5542670 & $0-0.85900600 \quad 0.32375300$ \\
\hline & -10.4862110 & $0-2.69187100-0.20326000$ \\
\hline & -12.8434440 & $0-1.27964500 \quad 0.27337400$ \\
\hline & $-11 \cdot 3686230$ & $0 \quad 0.18788800 \quad 0.57831100$ \\
\hline & -13.2565360 & $0-2.68550500-0.08123500$ \\
\hline & -14.0157700 & $0-0.37443600 \quad 0.59129900$ \\
\hline & -12.4110220 & $0-3.36017800-0.26549900$ \\
\hline & -13.8919970 & $0-2.68656900-0.98567200$ \\
\hline & -13.8703060 & $0-3.12611400 \quad 0.72541400$ \\
\hline & -6.94321200 & $-3.73685200-0.64049900$ \\
\hline & -8.51781700 & $-3.43152000-1.40417900$ \\
\hline & -8.43887000 & $-3.87645200 \quad 0.30773100$ \\
\hline & -1.50976300 & $-2.89943400-0.68368700$ \\
\hline & -3.06753200 & $-2.94145800-1.53556600$ \\
\hline & -2.98503400 & $-3.38752400 \quad 0.17627100$ \\
\hline & 1.50973700 & $2.89900000 \quad 0.68601100$ \\
\hline & 3.06778000 & 2.941130001 .53736100 \\
\hline & 2.98467200 & $3.38731000-0.17441700$ \\
\hline & 6.94307800 & $3.73667300 \quad 0.64254900$ \\
\hline & 8.43858100 & $3.87665300-0.30587900$ \\
\hline & 8.51782100 & $3.43125900 \quad 1.40589800$ \\
\hline & 12.41087500 & $3.36027500 \quad 0.26793300$ \\
\hline & 13.86920400 & $3.12733000-0.72466200$ \\
\hline
\end{tabular}




$\begin{array}{llll}\mathrm{H} & 13.89279900 & 2.68664400 & 0.98610200 \\ \mathrm{C} & -13.74896200 & 1.10930500 & 0.89522100 \\ \mathrm{H} & -14.55568700 & -0.81776500 & 1.45097100 \\ \mathrm{H} & -14.73832800 & -0.44015200 & -0.24694300 \\ \mathrm{C} & -13.32243400 & 1.91538200 & -0.30631900 \\ \mathrm{H} & -13.02751700 & 1.20168100 & 1.72242000 \\ \mathrm{H} & -14.69770300 & 1.52928500 & 1.28119300 \\ \mathrm{C} & -12.42811200 & 2.91748600 & -0.37023200 \\ \mathrm{H} & -13.84265000 & 1.65145100 & -1.23678400 \\ \mathrm{C} & -11.62931500 & 3.42835800 & 0.80314000 \\ \mathrm{H} & -11.80919200 & 2.86896300 & 1.73108500 \\ \mathrm{H} & -11.86659100 & 4.48948900 & 1.00151700 \\ \mathrm{H} & -10.54670800 & 3.39119900 & 0.58451800 \\ \mathrm{C} & -12.15506400 & 3.63086500 & -1.67208600 \\ \mathrm{H} & -12.76292300 & 3.23022400 & -2.49696900 \\ \mathrm{H} & -11.09048800 & 3.54299600 & -1.95631500 \\ \mathrm{H} & -12.36420600 & 4.71285400 & -1.58490700 \\ \mathrm{C} & 13.74895100 & -1.10813600 & -0.89677900 \\ \mathrm{H} & 14.73804100 & 0.44008500 & 0.24730900 \\ \mathrm{H} & 14.55596800 & 0.81944500 & -1.45027200 \\ \mathrm{C} & 13.32219300 & -1.91553800 & 0.30379700 \\ \mathrm{H} & 14.69774200 & -1.52772800 & -1.28305000 \\ \mathrm{H} & 13.02763100 & -1.19957900 & -1.72419600 \\ \mathrm{C} & 12.42823500 & -2.91805700 & 0.36629400 \\ \mathrm{H} & 13.84189100 & -1.65233900 & 1.23475800 \\ \mathrm{C} & 12.15488000 & -3.63287500 & 1.66729400 \\ \mathrm{H} & 12.76224100 & -3.23287000 & 2.49285200 \\ \mathrm{H} & 12.36444400 & -4.71469900 & 1.57908800 \\ \mathrm{H} & 11.09015100 & -3.54567800 & 1.95115500 \\ \mathrm{C} & 11.63019800 & -3.42804900 & -0.80797800 \\ \mathrm{H} & 11.81013700 & -2.86749600 & -1.73521200 \\ \mathrm{H} & 10.54748200 & -3.39174900 & -0.58975700 \\ \mathrm{H} & 11.86815400 & -4.48882100 & -1.00746300\end{array}$

\section{$\underline{\text { Spirilloxanthin }}$}

\section{$\mathrm{S}_{0}$ Geometry (B3LYP/cc-pVDZ):}
$\begin{array}{llll}\text { C } 18.25643200 & 2.32562000 & -0.70493500\end{array}$
C $17.31383500 \quad 1.29840100-0.06472800$
$\mathrm{H} 19.03094300 \quad 2.62501700 \quad 0.01701900$
$\mathrm{H} \quad 17.69380600 \quad 3.22734100 \quad-0.99142900$
$\mathrm{H} 18.74618700 \quad 1.91678700-1.60234800$
C $18.11736600 \quad 0.07012500 \quad 0.38460900$
$\mathrm{H} 18.60962200-0.39547200-0.48401000$
$\mathrm{H} \quad 17.49071900 \quad-0.69715100 \quad 0.86212900$
$\mathrm{H} \quad 18.90034200 \quad 0.36540200 \quad 1.10098200$ 
$\begin{array}{llll}0 & 16.74073900 & 2.02282400 & 1.04028900\end{array}$

C 16.158640001 .298420002 .10827800

H $16.91014100 \quad 0.75407400 \quad 2.71190700$

$\mathrm{H} \quad 15.38719700 \quad 0.58315700 \quad 1.77486600$

H $15.67953100 \quad 2.04760500 \quad 2.75687500$

C $16.21206000 \quad 0.93271200-1.10588900$

C $15.22182600-0.13807900-0.74808700$

H $16.74289900 \quad 0.61792600 \quad-2.02568700$

H $15.67576600 \quad 1.86377700-1.35008500$

C $13.88258100 \quad 0.04196700 \quad-0.72881500$

H $15.62881700-1.13288000-0.53789000$

C $12.87003000-0.96654900-0.43783800$

$\mathrm{H} \quad 13.49647900 \quad 1.04421500-0.95221200$

C $13.32835200-2.36929400-0.12894100$

H $13.90915200-2.78636400-0.96954200$

H $12.49587600 \quad-3.05407900 \quad 0.07405500$

H $13.99435000 \quad-2.38125500 \quad 0.75105600$

C $11.55299400-0.59085500-0.46059800$

C $10.39346300-1.40303100-0.20968800$

H $11.34634000 \quad 0.45953400 \quad-0.69914600$

C $9.11772100-0.91618600-0.25936900$

H $10.54595900 \quad-2.45757600 \quad 0.03158200$

C $7.90108500-1.65959300-0.02137500$

H $8.98701300 \quad 0.14499600 \quad-0.50311800$

C $8.00801200-3.12594700 \quad 0.31886100$

H $8.51841500-3.67990100-0.48728100$

H $7.03083100-3.59733100 \quad 0.47946600$

H $8.60570300-3.27423100 \quad 1.23431300$

C $6.70052200-0.99447200-0.11613500$

C $5.38130400-1.51839700 \quad 0.07621800$

H $6.75114200 \quad 0.07119000-0.37015800$

C $4.24996300-0.75612000-0.04464300$

H $5.27804500-2.57559300 \quad 0.33128900$

C $2.88996900-1.20176700 \quad 0.13220500$

H $4.37585100 \quad 0.30251300 \quad-0.30135700$

$\begin{array}{lllll}\text { C } 2.64341600 & -2.64776000 & 0.48742900\end{array}$

H $3.05421600-3.31783800-0.28671900$

$\mathrm{H} \quad 1.57794200-2.88221900 \quad 0.59893400$

H $3.14464900-2.91031400 \quad 1.43447700$

$\begin{array}{llll}\text { C } 1.87482400 & -0.28382200 & -0.03151900\end{array}$

$\begin{array}{llll}\text { C } 0.46745000 & -0.49378200 & 0.09243400\end{array}$

H $2.17800200 \quad 0.73813900-0.28928300$

C $-0.46751800 \quad 0.49409100 \quad-0.09194700$

H $0.10520900-1.49449200 \quad 0.34836300$

C $-1.87489100 \quad 0.28412600 \quad 0.03200800$

$\mathrm{H}-0.10528000 \quad 1.49480000-0.34788500$

C $-2.890041001 .20206400-0.13172900$ 


\begin{tabular}{|c|c|c|}
\hline & -2.17806400 & $-0.73783600 \quad 0.28977400$ \\
\hline & -2.64349700 & $2.64805100-0.48697600$ \\
\hline & -1.57801100 & -0.59826500 \\
\hline & -3.05449500 & 0.28705100 \\
\hline & -3.14454800 & -1.43414300 \\
\hline & -4.25003400 & 0.04509300 \\
\hline & -5.38138300 & $1.51865600-0.07583000$ \\
\hline & -4.37591200 & $-0.30222700 \quad 0.30182800$ \\
\hline & -6.70059700 & $0.99470800 \quad 0.11649300$ \\
\hline & -5.27813700 & -0.33093800 \\
\hline & -7.90117300 & $1.65979200 \quad 0.02164700$ \\
\hline & -6.75120000 & $-0.07094600 \quad 0.37055500$ \\
\hline & -8.00812600 & $3.12612500-0.3186$ \\
\hline & -7.03094500 & 3.59755200 \\
\hline & -8.51867600 & 3.68008500 \\
\hline & -8.60569100 & $3.27433800-1.2342$ \\
\hline & -9.11780000 & $0.91635600 \quad 0.25959600$ \\
\hline & -10.39355600 & 1.403150000 .20979 \\
\hline & -11.5 & $0.59093700 \quad 0.4$ \\
\hline & -12.8 & $0.96656400 \quad 0.43$ \\
\hline & -11.3463890 & $-0.45942800 \quad 0.69$ \\
\hline & -13.32849000 & $2.36926400 \quad 0.1287$ \\
\hline & -12.49602500 & $3.05409700-0.07$ \\
\hline & -13.9 & $2.78632300 \quad 0.9692$ \\
\hline & & $2.38115300-0.751$ \\
\hline & -13. & $-0.04199000 \quad 0.72 \varepsilon$ \\
\hline & -15.22190900 & $0.13798100 \quad 0.74777$ \\
\hline & -8.98707 & $-0.14480900 \quad 0.503$ \\
\hline & -10.54607 & $2.45767600-0.031$ \\
\hline & -13.49 & $-1.04420400 \quad 0.9521$ \\
\hline & -16.21211900 & -0.932852001 .105 \\
\hline & -15.62894400 & $1.13274000 \quad 0.53745$ \\
\hline & -17.31370900 & $-1.29871200 \quad 0.064$ \\
\hline & -16.74309300 & $-0.61802200 \quad 2.025$ \\
\hline & -15.67579400 & $-1.86385800 \quad 1.349$ \\
\hline & -16.74036600 & $-2.02330400-1.04$ \\
\hline & -16.15811500 & $-1.29904900-2.10$ \\
\hline & -15 & $-2.04831600-2.7$ \\
\hline & -15.38671200 & $-0.58373800-1.775$ \\
\hline & -16.90951400 & $-0.75477800 \quad-2.712$ \\
\hline & -18.25640000 & $-2.32586400 \quad 0.70442800$ \\
\hline & -17.69380900 & $-3.22750600 \quad 0.99123800$ \\
\hline & -19.0307110 & $-2.62542700-0.01766900$ \\
\hline & -18.74638600 & -1.916885001 .60165000 \\
\hline & -18.1171900 & $-0.07054100-0.38543000$ \\
\hline & 49047100 & $0.69668600-0.86293700$ \\
\hline & -18 & 0.395175000 .4 \\
\hline
\end{tabular}


$\mathrm{H}-18.90001000-0.36595500-1.10191700$

$\underline{\text { References }}$

(1) Richter, M.; Marquetand, P.; González-Vázquez, J.; Sola, I.; González, L. SHARC: Ab Initio Molecular Dynamics with Surface Hopping in the Adiabatic Representation Including Arbitrary Couplings. J. Chem. Theory Comput. 2011, 7 (5), 1253-1258. https://doi.org/10.1021/ct1007394.

(2) Mai, S.; Marquetand, P.; González, L. A General Method to Describe Intersystem Crossing Dynamics in Trajectory Surface Hopping. International Journal of Quantum Chemistry 2015, 115 (18), 1215-1231. https://doi.org/10.1002/qua.24891.

(3) Mai, S.; Marquetand, P.; González, L. Nonadiabatic Dynamics: The SHARC Approach. Wiley Interdisciplinary Reviews: Computational Molecular Science 2018, 8 (6), e1370. https://doi.org/10.1002/wcms.1370.

(4) Karlström, G.; Lindh, R.; Malmqvist, P.-Å.; Roos, B. O.; Ryde, U.; Veryazov, V.; Widmark, P.-O.; Cossi, M.; Schimmelpfennig, B.; Neogrady, P.; et al. MOLCAS: A Program Package for Computational Chemistry. Computational Materials Science 2003, 28 (2), 222-239. https://doi.org/10.1016/S0927-0256(03)00109-5.

(5) Aquilante, F.; Vico, L. D.; Ferré, N.; Ghigo, G.; Malmqvist, P.-åke; Neogrády, P.; Pedersen, T. B.; Pitoňák, M.; Reiher, M.; Roos, B. O.; et al. MOLCAS 7: The Next Generation. Journal of Computational Chemistry 2010, 31 (1), 224-247. https://doi.org/10.1002/jcc.21318.

(6) Aquilante, F.; Autschbach, J.; Carlson, R. K.; Chibotaru, L. F.; Delcey, M. G.; De Vico, L.; Fdez. Galván, I.; Ferré, N.; Frutos, L. M.; Gagliardi, L.; et al. Molcas 8: New Capabilities for Multiconfigurational Quantum Chemical Calculations across the Periodic Table. Journal of Computational Chemistry 2015, 37 (5), 506-541. https://doi.org/10.1002/jcc.24221. 